\title{
ENTRADA, CONCENTRACIÓN Y COMPETENCIA: SUPERMERCADOS EN CHILE 1998-2006*
}

\author{
Fernando Díaz, Alexander Galetovic \\ y Ricardo Sanhueza
}

\begin{abstract}
Entre 1998 y 2006 las ventas de supermercados se concentraron. En este trabajo se muestra que la expansión de Cencosud y D\&S hizo caer el precio relativo de los alimentos, intensificó la competencia en precios y atenuó la relación concentraciónprecio.

Se señala que manteniendo constante la concentración, la aparición de la primera cadena con centro de distribución nacional en una ciudad hace caer el precio relativo de los alimentos en
\end{abstract}

Fernando Díaz. Doctor en Economía, Universidad de Purdue. Profesor de la Universidad de los Andes.

Alexander Galetovic. Doctor en Economía, Universidad de Princeton. Profesor de la Universidad de los Andes e investigador del CEP.

Ricardo Sanhueza. Doctor en Economía, Universidad de Maryland. Profesor de la Universidad de los Andes.

* Una versión anterior de este trabajo fue encargada por Cencosud S. A. y presentada al Honorable Tribunal de Defensa de la Libre Competencia. Los datos que usamos nos fueron proporcionados gentilmente por Andrés Gómez-Lobo y Aldo González a través del Honorable Tribunal de Defensa de la Libre Competencia y por Cencosud S. A. No los verificamos en terreno porque es materialmente imposible hacerlo. Agradecemos los comentarios de Claudio Agostini, Rafael Gaete, Ricardo Paredes y Rodrigo Vergara y de los participantes en seminarios del Banco Central, el Centro de Estudios Públicos y Libertad y Desarrollo. Las opiniones expresadas en el trabajo son nuestras y no necesariamente coinciden con las de Cencosud S. A.

Estudios Públicos, 115 (invierno 2009). 
10,8\%. Cuando aparece la segunda cadena el precio relativo de los alimentos cae de nuevo. Ambas caídas suman 20,9\%.

La presencia de dos cadenas también debilita la relación entre concentración y precio. Si en una ciudad no hay ninguna cadena con un centro de distribución nacional y el número equivalente de firmas cae en uno, el precio relativo de los alimentos aumenta en $2,8 \%$. Una vez que aparece la primera cadena con centro de distribución nacional, el precio relativo de los alimentos aumenta menos, 1,4\%. Con dos cadenas pero con una firma equivalente menos, aumenta el precio en sólo $0,4 \%$.

Por último, aun si el número equivalente de firmas cayera en dos al completarse el ajuste, la entrada de dos cadenas hace caer el precio relativo en $20,1 \%$ — magnitud que, aunque mayor, es de similar orden que la caída del precio relativo de los alimentos a nivel nacional entre 1997 y 2007-.

Palabras clave: estructura de mercado; relación concentración-precio; centro de distribución.

\section{INTRODUCCIÓN}

\subsection{Contexto: una industria en cambio, movimiento y expansión}

L

a industria de los supermercados ha cambiado drásticamente durante los últimos diez años. Para comenzar, la tecnología de distribución es muy distinta. Si antes los proveedores abastecían y negociaban directamente con cada tienda, hoy hay dos cadenas que abastecen a sus tiendas desde un centro de distribución nacional y administran sus inventarios centralizadamente, y una tercera que construirá el suyo en breve plazo ${ }^{1}$. También es cierto que las tiendas de supermercado han evolucionado. Los hipermercados se han extendido por todo Chile y, durante el último tiempo, se han ido diferenciando distintos formatos, unos más pequeños, tales como los Ekono o los Líder Express, y otros grandes, tales como Mayorista 10, que vende grandes cantidades con descuento. Al mismo tiempo, dentro de cada tienda de supermercado el número de productos y servicios ofrecidos ha crecido y el ámbito se ha ampliado, para incluir bienes tales como ropa, artículos para el hogar y electrodomésticos. Por

${ }^{1}$ Una tercera cadena, SMU, ya anunció que construirá su centro de distribución. 
último, durante estos diez años las dos cadenas con centro de distribución se han extendido por todo Chile entrando en la mayoría de las ciudades, a veces adquiriendo cadenas locales, muchas otras instalando nuevas tiendas. La consolidación ha continuado durante los últimos dos años con la emergencia de Supermercados del Sur y SMU (dueña de Unimarc y Mayorista 10), que han adquirido varias cadenas locales e inaugurado nuevas tiendas.

Los cambios en Chile van a la par con los cambios en el resto del mundo. No hace tanto tiempo los supermercados eran el canal de distribución habitual sólo en países desarrollados, donde venden más de tres cuartos de los alimentos. Por contraste, en la generalidad de países como el nuestro tendían a ser la excepción, peculiaridades de los escasos barrios de ingresos medios y altos. Sin embargo, durante los últimos 15 ó 20 años las cadenas de supermercados se han difundido por el mundo en desarrollo en oleadas sucesivas, documentadas por Reardon et al. (2003) ${ }^{2}$. La primera ocurrió a partir de 1990 en gran parte de Sudamérica ${ }^{3}$, en el este asiático (excluido China), algunos países del sudeste asiático, el norte de Europa central y en Sudáfrica. La expansión ha sido bastante sorprendente. Por ejemplo, en 1990 sólo entre el 10 y 20\% de los alimentos vendidos en Sudáfrica se distribuía a través de supermercados; en 2008 la proporción había crecido a más de $50 \%$.

La segunda oleada ocurrió durante la segunda mitad de los años 90 en México $^{4}$, América Central ${ }^{5}$, parte del sudeste asiático y en el sur de Europa central ${ }^{6}$, donde la participación de los supermercados en las ventas de alimentos creció desde menos del 10\% hasta rangos de entre 30 y 50\%. Por último, la tercera oleada está ocurriendo desde el año 2000 en los países más pobres del este de Asia, incluyendo a China ${ }^{7}$, en la India, Europa oriental ${ }^{8}$ e incluso África.

\footnotetext{
${ }^{2}$ Véase también a Humphrey (2007), Reardon y Gulati (2008), Reardon et al. (2007)

${ }^{3}$ Véase por ejemplo a Faiguenbaum et al. (2004), Farina (2002), Gutman (2002), Reardon y Berdegué (2002), Rodríguez et al. (2002).

${ }^{4}$ Véase, por ejemplo, a Chávez (2002) y Schwentesius y Gómez (2002).

${ }^{5}$ Véase, por ejemplo, a Alvarado y Charmel (2002)

${ }^{6}$ Véase, por ejemplo, a Codron et al. (2004).

${ }^{7}$ Véase, por ejemplo, a Goldman (2000).

${ }^{8}$ Véase, por ejemplo, a Dries et al. (2004).
} 
La expansión de los supermercados no ha sido sólo cuestión de formato, sino también de cadenas. Lo habitual en países en desarrollo era que cada dueño de supermercados operase a lo más un par de tiendas; la expansión de los supermercados ha ido a la par con la emergencia y crecimiento de cadenas, cada una dueña de muchas tiendas. Una consecuencia es que durante estos 20 años la industria se ha consolidado, en parte mediante fusiones y adquisiciones, y en parte mediante la instalación de muchas tiendas de una cadena. Así, en cada país las ventas de supermercados se han concentrado. Por ejemplo, si en Brasil las diez cadenas más grandes vendían el 24,3\% del total de las ventas de supermercados en 1990, en 1999 la proporción había aumentado a 44,6\%. En Argentina, entre tanto, ocurrieron 13 fusiones y adquisiciones entre 1996 y 2000. El resultado es que en todas partes la industria aparece bastante concentrada. Por ejemplo, del total vendido por supermercados en 1999, las siete cadenas argentinas más grandes vendían el 77,5\%; las dos cadenas más grandes de Costa Rica vendían el $89 \%$ en 2001; y las tres cadenas mexicanas más grandes vendían el $81,1 \%$ en $2001^{9}$.

Tal como en el resto del mundo, en Chile los cambios tecnológicos y de organización han modificado la estructura de la industria. A nivel nacional, y tal como se aprecia en el Cuadro $\mathrm{N}^{\circ} 1$, las ventas de supermercados se han concentrado entre 1998 y 2006, principalmente, durante dos períodos cortos. Primero, entre 1997 y 1999, la suma de las dos mayores participaciones en las ventas de supermercados (D\&S y Santa Isabel) aumentó desde 33,20\% hasta 38,86\%. Este cambio refleja la expansión de D\&S a fines de la década pasada y coincidió con la entrada en servicio de su centro de distribución en octubre de 1997.

Segundo, entre 2002 y 2004, la participación sumada de D\&S y Cencosud aumentó desde 38,78\% hasta 58,60\%, fundamentalmente por la compra de Santa Isabel por Cencosud. En 2006 D\&S y Cencosud sumaban el 62,6\% de las ventas por supermercados, porcentaje que aumentó a cerca de $65 \%$ después de que Cencosud compró Economax e Infante en 2006, aunque la participación ha caído desde que surgieron Supermercados del Sur y SMU.

${ }^{9}$ La concentración de las ventas de alimentos es, por supuesto, bastante más baja, porque todavía una buena parte se vende en almacenes. 


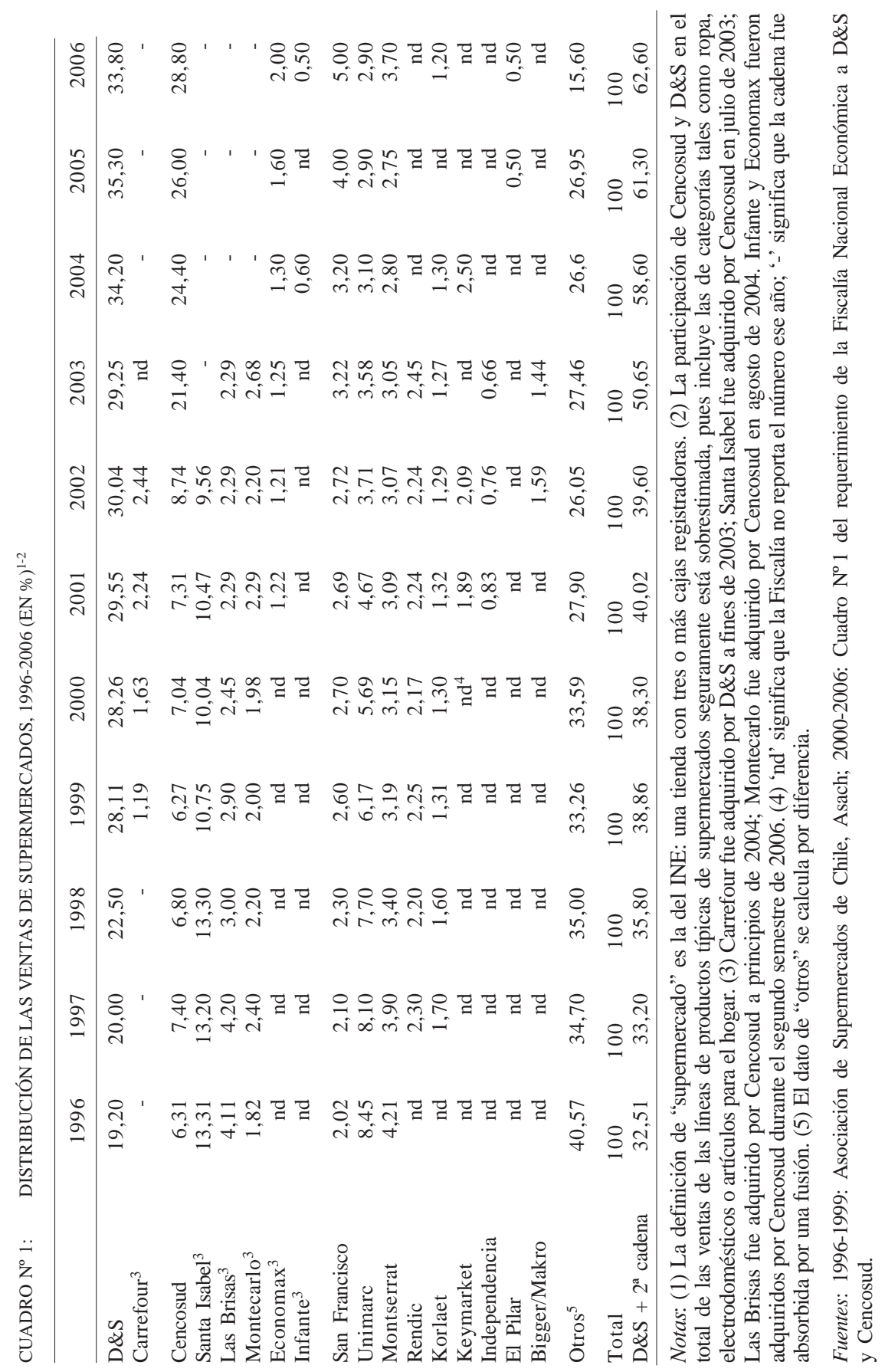




\subsection{La polémica en Chile}

La expansión de las cadenas de supermercados en Chile ha sido polémica, pues algunos sostienen que la concentración de las ventas ha sido dañina. Aguas arriba argumentan que las cadenas ejercerían poder de compra. Aguas abajo, la concentración permitiría cobrarles precios más altos a los consumidores. Tales aprensiones se manifestaron, por ejemplo, en 2006, cuando la Fiscalía Nacional Económica requirió a D\&S y Cencosud por

[desarrollar] desde hace varios años, agresivas y publicitadas estrategias de crecimiento, que comprenden, en modo sustancial, la toma de control de competidores y la adquisición de terrenos potencialmente aptos para instalar supermercados, con lo cual, por una parte, han eliminado competidores actuales y, por la otra, han levantado una fuerte barrera estratégica a la entrada de nuevos competidores, generando para sí un enorme poder de mercado, con el consiguiente riesgo de abuso, concertado o unilateral, para consumidores, competidores actuales y potenciales, y proveedores ${ }^{10}$.

Según la Fiscalía este poder fue ocupado para explotar a los proveedores:

A la par de lo anterior, tanto D\&S como Cencosud efectivamente han ejercido ese poder de mercado, específicamente su poder de compra, en contra de sus proveedores, imponiendo condiciones de compra subjetivas, discriminatorias y sorpresivas, y alterando ex post y unilateralmente las ya acordadas ${ }^{11}$.

Y aunque la Fiscalía reconocía no tener evidencia de que tales actos habían dañado a consumidores o competidores, tampoco creía que los hubieran beneficiado:

[...] si bien es cierto es discutible que [los consumidores] se hayan beneficiado de la concentración de la industria y de los términos de la relación de las requeridas con los proveedores, no existe evidencia de abusos.

${ }^{10}$ Requerimiento de la Fiscalía Nacional Económica en contra de D\&S y Cencosud del 18 de agosto de 2006, p. 2.

${ }^{11}$ Requerimiento, p. 2. 
Sin embargo, tesis como las de la Fiscalía conviven incómodamente con cuatro hechos. Uno es que, tal como se muestra en el Gráfico $N^{\circ} 1$, el precio relativo de los alimentos cayó $12,7 \%$ desde que entró el primer centro de distribución en 1997 y hasta $2007^{12}$. No sólo eso. Los aumentos de la concentración ocurrieron durante dos períodos breves, y en ninguno de los episodios aumentó el precio relativo de los alimentos. En efecto, tal como se aprecia en el Gráfico $\mathrm{N}^{\circ} 1$, buena parte de la caída del precio relativo de los alimentos ocurre entre 1997 y 2000, desde 100,0 hasta 90,7 a pesar de que entre 1997 y 1999 la participación de D\&S aumentó desde 20\% hasta 28,11\%, y que la suma de las participaciones de D\&S y Santa Isabel, en ese entonces las cadenas más grandes, aumentó desde 33,20\% hasta 38,86\%. De manera similar, el mayor aumento de la concentración ocurre entre 2003 y 2004, cuando Cencosud adquirió Santa Isabel, Las Brisas y Montecarlo, y D\&S compró Carrefour. Así, en apenas dos años la suma de las participaciones de D\&S y Cencosud aumentó desde 38,78\% en 2002 hasta 58,6\% en 2004. Sin embargo, entre 2002 y 2004 el precio

GRÁFICO No 1 : $\quad$ PRECIO RELATIVO DE LOS ALIMENTOS $(1997=100)$ Y PARTICIPACIÓN EN LAS VENTAS DE LAS DOS CADENAS MÁS GRANDES

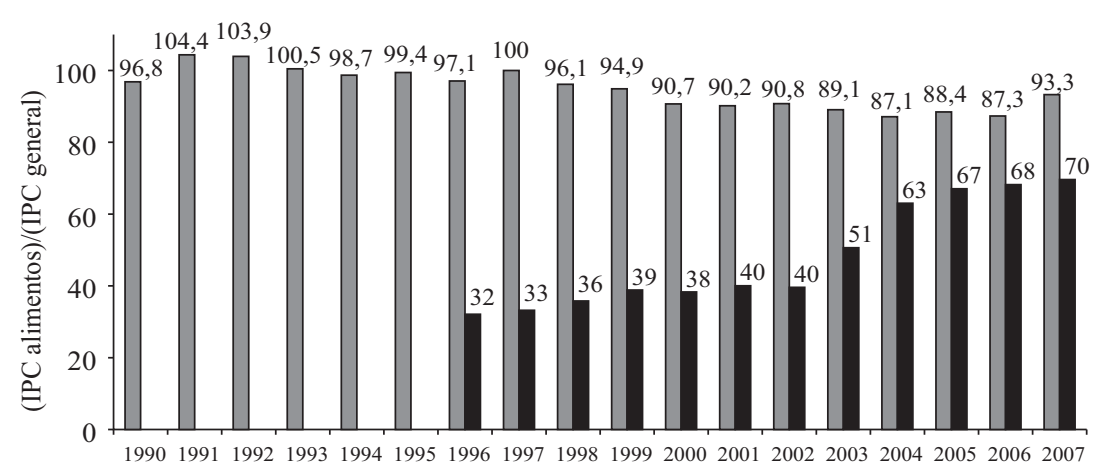

$\square$ Precio relativo de los alimentos

- Participación de las dos cadenas más grandes

\footnotetext{
12 Aunque, tal como se aprecia en el Gráfico Nº 1, aumentó en 2007, seguramente a consecuencia de heladas y sequías.
} 
relativo de los alimentos continuó cayendo, desde 90,8\% hasta 87,1\%. ¿Cómo es posible que aumente la concentración de las ventas de supermercados a nivel nacional y, al mismo tiempo, el precio de los alimentos caiga?

Segundo, la concentración de las ventas de supermercados en 24 ciudades no cambió entre 1998 y 2006 ${ }^{13}$. En efecto, en algunas ciudades cayó un poco, en otras aumentó un poco y la media simple del número equivalente de firmas apenas varió, desde 3,7 en 1998 hasta 4,0 en 2006. ¿Cómo es posible que el precio de los alimentos caiga en todo Chile sin que haya variado mucho la concentración en cada ciudad?

Tercero, mientras aumentaba la concentración de las ventas de supermercados a nivel nacional, las dos cadenas con centro de distribución se extendían por todo Chile. En realidad, buena parte del cambio estructural ocurrido entre 1998 y 2006 se manifestó en la entrada de las dos cadenas en varias ciudades de Chile.

Cuarto, la creencia de que en esta industria no se puede entrar es incoherente con el Cuadro $\mathrm{N}^{\circ}$ 2, el que muestra la entrada, salida $\mathrm{y}$ reemplazo de cadenas de supermercado en 16 ciudades chilenas entre 1998 y 2007 (en cada caso una entrada $(E)$ se denota con un número positivo, una salida $(S)$ con uno negativo y un reemplazo con una $r$ ). De las 95 entradas, apenas 13 corresponden a D\&S y Cencosud. Ambas cadenas son responsables de 19 de los 24 reemplazos. Pero en realidad tal suma esconde que Cencosud adquirió 18 cadenas, mientras que D\&S apenas una. Por eso, es claro que en esta industria se puede entrar y que las dos cadenas con centro de distribución nacional no han podido erigir una barrera estratégica a la entrada (sea lo que fuere que eso signifique $)^{14}$. Por supuesto, alguien podría argumentar que el gran número de salidas y reemplazos $(101+24$ en diez años o poco menos de 13 por año) implica que en esta industria "casi nadie, salvo los grandes, sobrevive”. Sin embargo, tal creencia ignora que a esta altura es ampliamente conocido que en la generalidad de las industrias alrededor del $10 \%$ de las firmas sale cada año, y éstas son reemplazadas por

${ }^{13}$ En ocho ciudades la información está disponible sólo desde 2002.

${ }^{14} \mathrm{Al}$ pasar, es conveniente notar que la evidencia tampoco respalda la creencia de que en esta industria no se puede entrar porque no habría terrenos disponibles. En efecto, de acuerdo con datos de la Asociación de Supermercados, en 1996 había en Santiago 196 tiendas de supermercado. Entre 1996 y 2006 se cerraron 92 locales y se abrieron 138 en nuevas ubicaciones; es decir, poco más de una de cada dos tiendas de supermercado en 2006 no estaba en 1996, y 92 localizaciones habían dejado de ser supermercados. 


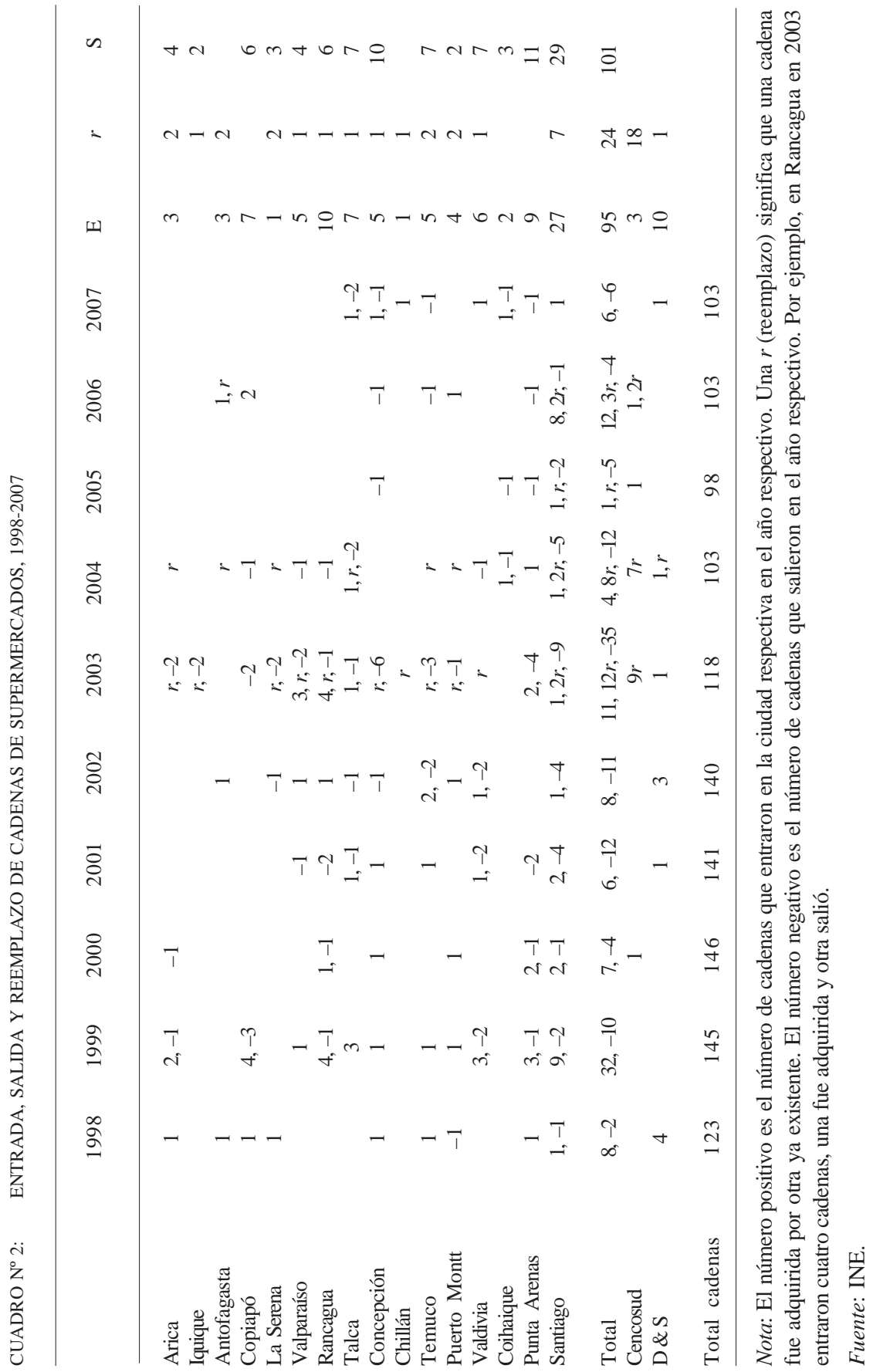


una magnitud similar de entrantes ${ }^{15}$. En este caso, tal como indica la última línea del Cuadro $\mathrm{N}^{\circ} 2$, el número de cadenas de supermercados en las 16 ciudades es entre 98 y 146. Por lo tanto, las tasas brutas de entrada y salida son del orden del $10 \%$ y nada tienen de atípicas si se les compara con la generalidad de las industrias.

¿Cómo se pueden conciliar estos hechos? Seguramente ningún economista argumentaría que el aumento de la concentración a nivel nacional causó la caída del precio relativo de los alimentos. Sin embargo el punto es otro, a saber, que cuando ocurren cambios estructurales en una industria, es posible que un tercer factor aumente permanentemente la concentración y haga caer permanentemente los precios. En este caso nuestra tesis es que el tercer factor son los centros de distribución nacional y las mejoras de gestión que permite la profesionalización de las empresas. D\&S y Cencosud son competidores distintos porque, al operar desde un centro de distribución nacional, sus costos marginales y medios son más bajos ${ }^{16}$. De un lado, la caída de los costos marginales cambia la competencia entre supermercados en el corto plazo. De otro lado, los menores costos medios estimulan la expansión y entrada de las cadenas. Esto aumenta la concentración a nivel nacional, aunque no necesariamente en cada ciudad.

\subsection{La evidencia que aporta este trabajo}

En este trabajo no mostraremos evidencia directa de costos marginales o medios porque es difícil estimar ahorros de costos y luego desentrañar el mecanismo que los traslada hacia menores pre$\operatorname{cios}^{17}$. Sin embargo, es posible testear las implicancias observables de

${ }^{15}$ Véase, por ejemplo, a Baldwin (1998), Bartelsman y Doms (2000), Bartelsman et al. (2004), Caves (1998) o Geroski (1991). Sobre Chile véase a Benavente et al. (2005) y Cabrera et al. (2002).

${ }^{16}$ La irrupción de los centros de distribución es un cambio estructural que ha afectado al retail en todo el mundo. Por ejemplo, un estudio del Food Market Institute de los Estados Unidos muestra que la operación centralizada y verticalmente integrada de la distribución y retail permite una logística considerablemente más eficiente. Ellickson (2007) también estudia las consecuencias de los centros de distribución en la industria de los supermercados en los Estados Unidos.

${ }^{17}$ Sin embargo, Lira y Ugarte (2007) encuentran que la razón

gastos de administración y ventas ingresos

una proxie de costos variables, cayó desde 22\% en 1998 hasta 11\% en 2006. 
la caída de costos marginales estimando una relación concentraciónprecio en la medida en que, al mismo tiempo, uno se haga cargo del cambio estructural. La aparición de cadenas con centro de distribución en distintas ciudades de Chile en momentos distintos permite hacerse cargo del cambio estructural.

Mostramos que, manteniendo constante la concentración, la aparición de la primera cadena con un centro de distribución nacional hace caer el precio relativo de los alimentos $10,8 \%^{18}$. Y si a la primera cadena se le agrega la segunda, el precio relativo de los alimentos cae $20,9 \%$ en total.

Más aun. Si en una ciudad no hay ninguna cadena con un centro de distribución nacional, y el número equivalente de firmas cae en uno, el precio relativo de los alimentos aumenta en 2,8\% —ésta es la tradicional relación concentración-precio— ${ }^{19}$. Sin embargo, una vez que aparece la primera cadena con un centro de distribución nacional, la relación concentración-precio se atenúa: si el número equivalente de firmas cae en uno, el precio relativo de los alimentos aumenta $1,4 \%$. La presencia de la segunda cadena restringe el aumento a sólo 0,4\%. En realidad, un test de Wald no permite rechazar la hipótesis nula de que la relación concentración-precio desaparece.

Por eso, aun si al completarse el ajuste el número equivalente de firmas cae en dos, la presencia de dos cadenas hace caer el precio relativo en $20,1 \%$ — magnitud algo mayor que la caída del precio

${ }^{18}$ En adelante usaremos el término "aparición” de una cadena con centro de distribución nacional en una ciudad dada. La aparición puede ocurrir por entrada (v. gr. D\&S instala su primer supermercado en Copiapó en 2005 y lo abastece desde su centro de distribución, construido en 1997). O bien porque una cadena que ya atiende a una ciudad instala su centro de distribución (v.gr. una cadena con centro de distribución nacional apareció en Chillán en 2000 cuando Santa Isabel instaló su centro de distribución, a pesar de que Santa Isabel ya estaba presente en esa ciudad).

19 La concentración se mide tradicionalmente con el índice de HerfindahlHirschman. Se define el índice de Herfindahl-Hirschman como

$$
\mathcal{H}=\sum_{i=1}^{n} s_{i}^{2}
$$

donde $s_{i} \in[0,1]$ es la participación de mercado de la $i$ ésima empresa. El número equivalente de firmas es igual a $\frac{1}{\mathcal{H}}$ (véase a Adelman, 1969) — es el número de firmas con igual participación de mercado que da por resultado un valor particular del índice de Herfindahl-Hirschman-. En adelante usaremos el número equivalente de firmas porque es más fácil pensar en términos de número de firmas que en términos de un índice abstracto. 
relativo de los alimentos a nivel nacional pero de orden de magnitud similar- Así, el precio relativo de los alimentos cae fuertemente con la presencia de dos cadenas con centro de distribución nacional y la relación concentración-precio se atenúa al punto de casi desaparecer - es como si la competencia fuera perfecta-.

En conclusión, nuestros resultados indican que las cadenas con centro de distribución nacional han hecho caer significativa y permanentemente el precio relativo de los alimentos y que la concentración aguas abajo no ha variado mayormente durante estos últimos ocho años. Por cierto, a nivel nacional las ventas se han concentrado, porque hay cuatro cadenas que tienen tiendas de supermercado en la mayoría de las ciudades. En esencia, nuestros resultados sugieren que cuando hay dos cadenas con centro de distribución nacional en una ciudad, la competencia en precios es mucho más intensa que antes.

La transformación de la industria de los supermercados chilena y su evolución reciente ha sido bastante estudiada ${ }^{20}$. Los trabajos más cercanos al nuestro son los de Lira, Rivero y Vergara (2007) y Lira, Ugarte y Vergara (2007 y 2008). El primer trabajo estimó el efecto de la entrada de una tienda de hipermercado sobre el precio relativo de los alimentos con un panel de 15 ciudades chilenas entre 1998 y 2004. Encontraron que la apertura de un hipermercado hace caer el precio relativo de los alimentos entre 7 y 11\%. Lira, Ugarte y Vergara (2007) controlaron además por la concentración en cada ciudad con el índice de Herfindahl-Hirschman y extendieron el panel hasta el segundo trimestre de 2006. Tal como nosotros, encontraron que el efecto de la entrada (en este caso de un hipermercado) es un orden de magnitud mayor que el efecto de quitar una firma equivalente. Lira, Ugarte y Vergara (2008), por su parte, confirman que los precios caen en una ciudad con la entrada de la primera cadena nacional, y vuelven a caer cuando entra la segunda. Más aun, a medida que la suma de la participación en las ventas de D\&S y Cencosud aumenta, los precios caen aun más. Por último, nuestro trabajo también está relacionado con el de Gómez-Lobo y González (2007), quienes estiman una relación concentración-precio. Ellos obtienen resultados un tanto diferentes a los nuestros. Para explicar el porqué de las diferencias, en el Apéndice B comentamos detalladamente este estudio.

${ }^{20}$ Véanse, por ejemplo, Calderón (2006), Coloma et al. (2007), Faiguenbaum et al. (2004), Galetovic y Sanhueza (2006), Lira (2005), Rojas (2007) y Lira y Ugarte (2007). 


\subsection{El resto de este trabajo}

El resto de este trabajo explica la teoría (sección 2). Luego explica cómo estimar la relación concentración-precio cuando una industria vive un cambio estructural, y por qué cuando se ignora ese cambio se introduce un sesgo por variables omitidas (sección 3). En la sección 4 estimamos el efecto directo de la presencia de cadenas con centro de distribución. En la sección 5 discutimos varias implicancias de nuestros resultados que permiten poner en perspectiva lo ocurrido en la industria de los supermercados entre 1998 y 2006. Finalmente, en un epílogo comentamos brevemente un fallo reciente del Tribunal de la Libre Competencia.

\section{LA RELACIÓN CONCENTRACIÓN-PRECIO Y LA ESTRUCTURA INDUSTRIAL DE EQUILIBRIO}

Nuestro análisis del cambio estructural se basa en la estimación de una relación concentración-precio estándar. En esta sección aplicamos las ideas desarrolladas por Sutton (1991) sobre los determinantes de la estructura industrial de equilibrio para entender las consecuencias del cambio estructural sobre la relación concentración-precio ${ }^{21}$. Este análisis de equilibrio ilustra la mecánica de los cambios, fundamenta la estimación econométrica y advierte sobre los posibles errores de especificación que se pueden cometer.

\subsection{Estructura industrial de equilibrio}

En el modelo más simple de estructura industrial de equilibrio las firmas son idénticas y el tiempo se divide en dos períodos: en el primero (el largo plazo) las firmas deciden si acaso entran al mercado. En el segundo (el corto plazo), el número fijo de firmas que entraron compite (véase el Gráfico $\mathrm{N}^{\circ}$ 2).

En este modelo las condiciones de equilibrio son tres. La primera dice que en el corto plazo (período 2) el precio de mercado del bien será igual al costo marginal aumentado por el margen precio-costo la nuestra.

${ }^{21}$ Véase a Symeonidis (2002, cap. 4) para una formulación aun más general que 
GRÁFICO No 2: EL MODELO DE DOS PERÍODOS

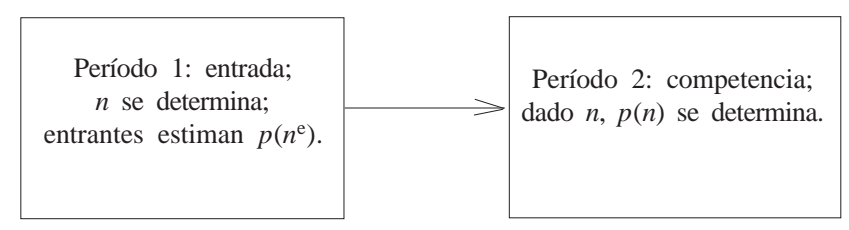

marginal de equilibrio. Sea $p$ el precio de mercado, $q$ la cantidad producida por la firma y $c_{\mathrm{mg}}$ la función de costo marginal. Entonces

$$
p=[1+v(n ; \tau(\theta))] \cdot c_{\mathrm{mg}}(q ; \theta) .
$$

Donde $\theta$ es un vector de parámetros tecnológicos que afectan a la función de costos; así, por convención, mientras mayor sea un componente $\theta$ del vector, menor será el costo marginal y medio, todo lo demás constante; y $v(n ; \tau(\theta)$ es el margen o mark up sobre costo marginal que, supondremos, es función de $n$, el número de firmas activas, y $\tau(\theta)$, una medida de la intensidad de la competencia en precios (este concepto se explicará en la siguiente subsección), que también depende, en principio, del vector de parámetros tecnológicos $\theta$.

La segunda condición es que la cantidad demandada sea igual a la cantidad ofrecida por las $n$ empresas en el mercado, a saber

$$
D(p)=n q,
$$

donde $D$ es la función de demanda.

Por último, en el equilibrio de largo plazo entrarán firmas hasta que cubran exactamente los costos de establecerse. Si para entrar en el período 1 se necesita invertir $\sigma(\theta)$, la condición de cero utilidades es

$$
\left[p-c_{\mathrm{me}}(q ; \theta)\right] \times q=\sigma(\theta),
$$

donde $c_{\text {me }}(q ; \theta)$ es el costo medio de corto plazo de producir $q$. Vale decir, en este mercado hay libre entrada: cualquiera que pague el costo de entrar $\sigma(\theta)$ puede entrar. 
Ahora bien, las variables endógenas son $p, q$ y $n$. La combinación $\left(p^{*}, q^{*}, n^{*}\right)$ es de equilibrio cuando satisface simultáneamente (2.1), (2.2) y (2.3). Estas tres condiciones son estándares, pero conviene mirarlas desde una perspectiva algo distinta de la habitual.

Para comenzar, nótese que (2.1) y (2.2) son condiciones de equilibrio de corto plazo — vale decir, se cumplirán en todo momento, independientemente de si la industria esté o no en equilibrio de largo plazo- - La razón es que en el corto plazo el número de firmas es fijo $\mathrm{y}$, dado $n$, podemos determinar el precio de equilibrio y la cantidad producida por cada firma.

Para el análisis antimonopolio es crucial la relación entre $n$ y $p$ —la relación concentración-precio—- De la gran mayoría de los modelos de competencia se obtendrá que si las funciones de costo y demanda satisfacen condiciones estándares, el precio de equilibrio será mayor mientras menos firmas participen en el mercado ${ }^{22}$. En el Gráfico $\mathrm{N}^{\circ} 3$ se expresa esta relación con la curva $p p$ : mientras menor es $n$ mayor es $p$.

Como se dijo, la pendiente negativa de la curva $p p$ es predicha por casi cualquier modelo teórico (véase Sutton [1991]) y tiene fuerte respaldo empírico (véase por ejemplo Weiss [1989]). De un lado, a medida que aumenta el número de firmas el margen $v$ debiera caer (por ejemplo, así ocurre en el modelo estándar de Cournot). Es decir, en términos de la expresión (2.1), $v_{n}<0$, vale decir, el precio cae a medida que aumenta el número de firmas. Del otro lado, todo lo demás constante, la participación de mercado y la cantidad producida por cada firma debieran ser menores. Por eso, el costo marginal de cada firma debiera ser menor y, también por eso, mientras mayor sean, menor será el precio de equilibrio.

Es importante precisar que la teoría deduce y la evidencia empírica reporta una relación todo lo demás constante: a medida que cae el número de firmas el precio de equilibrio es mayor. El "todo lo demás constante” indica que se trata de una relación de corto plazo que supone variaciones exógenas del número de firmas. Es por eso que tiene sentido estimar una relación concentración precio.

22 Esta regularidad aparece, por ejemplo, en el modelo estándar de Cournot, pero también en una serie de otros modelos tales como los de productos diferenciados à la Salop, de variaciones conjeturales, el supply function equilibria de Klemperer y Meyer (1989). Y, más importante, ha sido establecida empíricamente por una serie de estudios, entre ellos el clásico de Leonard Weiss (1989). Véase Gómez-Lobo y González (2007, Cuadro $N^{\circ} 1$ ) para una lista de estudios sobre esta relación. 
GRÁFICO N ${ }^{\circ}$ 3: $\quad$ ESTRUCTURA INDUSTRIAL DE EQUILIBRIO Y LAS CONSECUENCIAS DE LA COMPETENCIA MÁS INTENSA

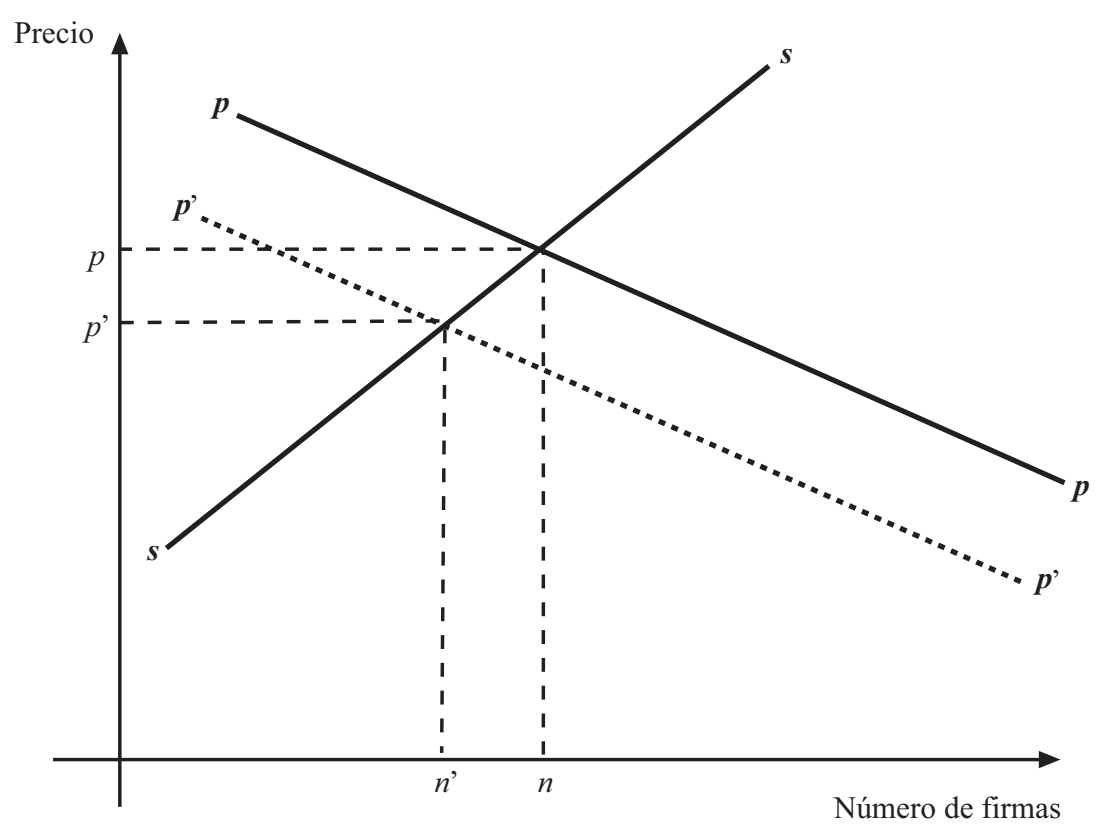

Ahora bien, en el corto plazo es claro que $n$ es exógeno. Pero si la entrada al mercado es libre, la estructura de equilibrio también determina $n$ —en el largo plazo la concentración es una variable endógena-23. Eso no impide estimar la relación concentración-precio, pero implica que la curva $p p$ no basta para estudiar los determinantes de la estructura industrial de equilibrio.

Para completar el modelo, por tanto, es necesaria la condición de equilibrio de largo plazo (2.3) que determina n. Aquí no hay nada nuevo, excepto que esta condición implica que mientras mayor sea el precio de equilibrio de largo plazo, mayor será el número de firmas — vale decir, la relación es opuesta a la estándar "menos firmas-

${ }^{23}$ Vale la pena precisar que la entrada libre no significa que sea gratis, sino sólo que es libre de entrar quien esté dispuesto a pagar los costos de entrada. 
mayor precio" -24 . Vale la pena detenerse un instante para apreciar por qué.

Una manera alternativa de interpretar la condición (2.3), $\left[p-c_{\text {me }}(q ; \theta)\right] \times q=\sigma(\theta)$, es que en equilibrio de largo plazo el precio $p$ debe ser tal que el margen por venta $\left[p-c_{\text {me }}(q ; \theta)\right]$ multiplicado por el volumen $q$ debe cubrir el costo de entrada $\sigma(\theta)$. Esto permite apreciar que, grosso modo, mientras mayor sea el precio, el volumen $q$ necesario para cubrir $\sigma(\theta)$ será menor.

Ahora bien, dado un precio $p$, la cantidad demandada en el mercado es $D(p)$ y el volumen por firma es $q=\frac{D(p)}{n}$. Por eso, podemos volver a escribir la condición (2.3) como

$$
\left\{p-c_{\mathrm{me}}\left[\frac{D(p)}{n}, \theta\right]\right\} \times \frac{D(p)}{n}=\sigma(\theta) .
$$

Es fácil apreciar ahora que si el volumen por firma cae porque el precio de largo plazo es mayor, entonces “caben” más firmas en el mercado. En el Gráfico № 3 se expresa esta relación con la curva ss: mientras mayor es $n$ mayor es $p$.

La estructura de equilibrio se encuentra donde las curvas $p p$ y $s s$ se intersectan (véase el Gráfico $\mathrm{N}^{\circ} 3$ ). Esto permite separar el análisis en dos partes: de un lado, la curva $p p$ resume cómo compiten las firmas que ya entraron al mercado. En el corto plazo, $n$ es fijo, sólo los costos marginales son relevantes y el equilibrio de la industria ocurre sobre la curva $p p$. Del otro lado, la curva ss resume los determinantes de la entrada al mercado. En equilibrio de largo plazo la competencia de corto plazo debiera entregar márgenes precio-costo medio suficientes para que las firmas cubran sus costos de entrada y obtengan rentabilidades normales. Aquí ya no son importantes los costos marginales sino los costos medios.

${ }^{24}$ Demostración: Sean $\left[p-c_{\text {me }}(q)\right] D(p)$, las utilidades agregadas de todas las firmas al precio $p$. Si los costos de inversión son iguales a $\sigma$, entonces para que las firmas obtengan cero utilidades se debe cumplir que

$$
\left[p-c_{\mathrm{me}}(q)\right] \frac{D(p)}{m} \equiv \sigma .
$$

Ahora bien, bajo condiciones estándares, mientras $p$ sea menor que el precio monopólico, $\left[p-c_{\text {me }}(q)\right] D(p)$ es creciente en $p$ y decreciente en $m$, lo que establece el resultado. 


\subsection{Competencia en precios}

En el análisis de la estructura industrial de equilibrio son centrales la posición y la pendiente de la curva $p p$. La pendiente depende de la magnitud de la derivada $v_{n}$ y de la pendiente de la curva de costo marginal. La posición de la curva, en tanto, depende de lo que Sutton (1991) llama "la intensidad de la competencia en precios" (toughness of price competition), $\tau(\theta)$. A continuación explicamos este concepto.

La intensidad de la competencia en precios. Consideremos primero la intensidad de la competencia en precios y recordemos que en el equilibrio de corto plazo

$$
p=[1+v(n ; \tau(\theta))] \cdot c_{\mathrm{mg}}(q(n) ; \theta)
$$

donde la producción de cada firma depende de $n$. Así, mientras mayor es $v$, más intensa es la competencia y menor el margen precio-costo marginal de equilibrio para cada $n$. Por eso, cuando $\tau(\theta)$ aumenta, la curva $p p$ se desplaza hacia abajo — para cada $n$, el precio de equilibrio es menor-.

¿De qué depende la intensidad de la competencia en precios? La legión de modelos que ha desarrollado la teoría moderna de la Organización Industrial puede entenderse como una exploración sistemática de sus determinantes. Sabemos, por ejemplo, que la diferenciación de productos tiende a relajarla, lo mismo que los costos de cambiarse de proveedor (los así llamados switching costs), la colusión o el hecho de que los clientes deban incurrir en costos de traslado para llegar a los distintos proveedores. Pero, en último término, la intensidad de la competencia en precios siempre depende de cuánto gane una empresa si compite más agresivamente. Si gana mucho, entonces la competencia en precios será intensa; y lo opuesto será cierto si gana poco.

Este principio se puede ilustrar con una identidad muy simple en un modelo de productos homogéneos donde se compite en cantidades. La ganancia obtenida por la empresa $i$ si produce $\Delta q_{i}$ más, llamémosla $\Delta \pi_{i}$, es igual a la diferencia entre el aumento de los ingresos $\left(\Delta I_{i}\right)$ y el aumento de costos $\left(\Delta c_{i}\right)$. Es decir 


$$
\Delta \pi_{i} \equiv \Delta I_{i}-\Delta c_{i}
$$

Esta diferencia se puede descomponer de la siguiente forma:

$$
\Delta I_{i}-\Delta c_{i} \approx\left(q_{i} \cdot \frac{d p}{d q_{i}}+p\right) \Delta q_{i}-c_{\mathrm{mg}} \Delta q_{i}=\left[\left(p-c_{\mathrm{mg}}\right)+q \frac{d p}{d q_{i}}\right] \Delta q_{i} .
$$

El primer término de la expresión (2.4) indica que una desviación unilateral aumenta las ventas de la empresa; cuánto gane dependerá del margen. La segunda parte indica que una desviación unilateral disminuye el ingreso generado por $q$, cantidad que la empresa hubiera vendido de todos modos. Así, un margen $p-c_{\text {mg }}$ grande o una respuesta apreciable del precio a variaciones de la cantidad ( $\left|\frac{d p}{d q_{i}}\right|$ grande) implican que la competencia en precios es intensa.

Para apreciar cómo se puede usar esta identidad para entender los determinantes de la intensidad de la competencia en precios, examinamos a continuación cuatro ejemplos.

Ejemplo 1: Considérese el ejemplo canónico (aunque extremo) de competencia à la Bertrand entre empresas cuyos costos medios son iguales y constantes y que producen un bien homogéneo. En ese caso $\left|\frac{d p}{d q_{i}}\right|=0 \mathrm{y}\left(p-c_{\mathrm{mg}}\right) \cdot \Delta q_{i}$ es "grande", a menos que $p=c_{\mathrm{mg}}$. Por eso, la competencia es intensa y los precios tales que $p-c_{\text {me }}>0$ son insostenibles.

Ejemplo 2: De manera similar, en un mercado perfectamente competitivo $\left|\frac{d p}{d q_{i}}\right|=0$. Por lo tanto, los márgenes por encima de $p-c_{\mathrm{mg}}$ $>0$ son insostenibles aun en el corto plazo, porque se puede vender mucho más sin perder ingresos por las ventas que se hubieran hecho de todos modos.

Ejemplo 3: Por el contrario, supóngase que cambiarse de proveedor es engorroso porque hay que romper un contrato y entrevistarse con vendedores de la competencia para averiguar condiciones y precios. En ese caso $\left|\frac{d p}{d q_{i}}\right|$ es grande —un pequeño aumento de las ventas implica una gran caída del precio-y, por eso, disminuyen fuertemente el margen y los ingresos por ventas a clientes que ya se tienen. Por tanto, la competencia en precios no es intensa. 
Ejemplo 4: Por último, considérese el caso canónico de la colusión sostenida por castigos en un juego repetido. La colusión aumenta el margen $p-c_{\mathrm{mg}}$; el rol del castigo es que $\left|\frac{d p}{d q_{i}}\right|$ sea grande en el largo plazo.

Es importante notar que en algunos casos la intensidad de la competencia en precios depende de parámetros estructurales (o exógenos), que son independientes de las decisiones de las empresas. Por ejemplo, la intensidad de la competencia entre tiendas de retail de una ciudad depende de los costos de ir de una a otra, y son influenciados por la disponibilidad de medios de transporte. En otros casos, sin embargo, las empresas toman decisiones estratégicas para relajar la competencia. Por ejemplo, una de las razones que justifican elegir un estándar técnico distinto al de un competidor es aumentar los costos de cambiarse.

Costos marginales. La posición de la curva pp también depende del costo marginal. Todo lo demás constante, un cambio tecnológico que los disminuya también debiera disminuir directamente el precio de equilibrio dado el número de firmas $n$.

La intensidad de la competencia en precios y la pendiente de la curva pp. Por último, un cambio en la intensidad de la competencia en precios también podría afectar la pendiente de la curva $p p$. Formalmente, la magnitud de este cambio se mide por la derivada cruzada $v_{n, \tau}<0$.

¿Por qué podría ocurrir que la competencia en precios más intensa atenúe la relación entre concentración y precio? Considérese un cambio de $\theta$ tal que la curva de costo marginal de cada firma caiga y se aplane. En ese caso, la competencia en precios es más intensa dado $n$, por las razones que se deducen de la expresión (2.4). Al mismo tiempo, ahora el precio debería aumentar menos si sale una firma, porque para cada firma el costo de aumentar la producción un poco crece lentamente al ser más plana la curva de costo marginal. Líneas abajo testearemos esta hipótesis en el caso de la industria de los supermercados entre 1998 y 2006. 
Una breve digresión sobre mercados desafiables. Para terminar, conviene explicar por qué este análisis de la estructura de mercado de equilibrio es distinto de la teoría de los mercados desafiables de Baumol et al. (1982). Tanto en esta teoría como en la de mercados desafiables la entrada juega un rol primordial. Sin embargo, en este análisis los precios responden a la entrada efectiva, mientras que en la de mercados desafiables, a la entrada potencial. Por eso, la teoría de los mercados desafiables implica que la curva $p p$ es plana al nivel del costo medio de largo plazo: da lo mismo el número de empresas, el precio es siempre el mismo y determinado por la amenaza de entrada. En esta teoría, por contraste, las firmas compiten y afectan el equilibrio sólo si están dentro del mercado - la entrada no lo influye hasta que se materializa—. Precisamente por eso es posible estimar una relación concentración-precio suponiendo que el número de firmas es exógeno.

\subsection{La relación concentración-precio y los cambios estructurales}

Menores precios y mayor concentración. Como se vio líneas arriba, la estructura de equilibrio se encuentra donde se intersectan la curva $p p$ y la curva ss. Pero la implicancia más relevante para lo que aquí nos interesa es ésta: en el largo plazo la concentración es mayor mientras más intensa sea la competencia en precios.

Para entender por qué, es conveniente volver al Gráfico No 3 . Supóngase un cambio “tecnológico” que no afecte los costos pero intensifique la competencia en precios $(\tau(\theta)$ aumenta). Cuando esto ocurre el precio de equilibrio cae para cada $n$-la curva $p p$ se desplaza hacia abajo- - Si el número de firmas permaneciera constante, el margen precio-costo medio ya no sería suficiente para cubrir el costo de entrada $\sigma(\theta)$. Para cubrirlo, el volumen vendido por cada firma debe aumentar, y eso sólo es posible si el número de firmas cae desde $n$ hasta $n^{\prime}$. Por eso, es perfectamente posible que en un mercado se observen episodios donde aumente simultáneamente la concentración y caigan los precios. Obviamente no se trata de que la mayor concentración cause la caída en precios. El punto es que un tercer factor (en este caso la competencia en precios más intensa) puede hacer caer los precios y aumentar la concentración simultáneamente. 
Cambios de los costos marginales. De manera similar, una caída del costo marginal desplaza la curva $p p$ hacia abajo y posiblemente disminuya su pendiente. Sin embargo, la concentración no caerá necesariamente en equilibrio de largo plazo, porque al caer los costos la curva ss se desplaza hacia la derecha. Por eso, aunque el efecto sobre la $p p$ es similar al de un aumento en la intensidad de la competencia en precios, el efecto sobre el equilibrio de largo plazo es distinto.

\section{ESTIMACIÓN DE LA PENDIENTE DE LA CURVA pp CUANDO HAY CAMBIO ESTRUCTURAL}

\subsection{Usando el modelo: la industria de los supermercados 1998-2006}

Nuestro modelo se puede usar para ilustrar las implicancias observables de los cambios estructurales que afectaron a la industria de los supermercados entre 1998 y 2006. Por cierto, en la breve discusión que sigue no pretendemos usarlo para describir la evolución de la industria. El modelo es insuficiente, entre otras cosas, porque ignora la heterogeneidad entre firmas. Por eso, el propósito de lo que sigue sólo es ilustrar aquellos efectos que luego se estimarán empíricamente.

\subsection{Identificación y estimación de las curvas pp y ss}

¿Se puede estimar un modelo como el descrito? Estimar la curva ss es muy difícil porque sería necesario una sección cruzada de industrias con costos medios y de entrada similares, pero con distintas intensidades de competencia en precio. Medir directamente la intensidad de la competencia en precios es casi imposible, lo que impide estimar.

En cambio, es posible estimar la curva $p p$. En efecto, cuando se trata de la misma industria, pero existen suficientes mercados distintos y separados temporal o geográficamente, es razonable pensar que la relación entre concentración y precios es similar en todas ellas. Si así fuera, y en vista de que esta relación opera en el corto plazo, bastaría con tomar la concentración como variable exógena; si la industria está 
o no en equilibrio de largo plazo por movimientos de la curva ss es, en principio, irrelevante.

Sin embargo, en este caso es necesario hacerse cargo de los cambios estructurales que han ocurrido entre 1998 y 2006. En particular, nuestra tesis es que esos cambios han disminuido los costos marginales y, tal vez, la forma de competir y con ello la pendiente de la relación entre concentración y precios.

Las posibles consecuencias de estos cambios se pueden apreciar con la ayuda del Gráfico $\mathrm{N}^{\circ} 4$. Supongamos que antes de los cambios estructurales (v. gr. en 1996) la industria se encuentra en equilibrio en una ciudad dada en un punto $A$ como con, digamos, tres firmas. $\mathrm{Al}$ ocurrir el cambio estructural suceden, en principio, cuatro cosas.

Primero, la curva ss relevante para firmas que cuentan con la nueva tecnología se desplaza hacia la derecha. Este desplazamiento indica que es rentable entrar con la nueva tecnología en esa ciudad a

GRÁFICO N 4: $\quad$ ESTRUCTURA INDUSTRIAL Y CAMBIO ESTRUCTURAL EN LA INDUSTRIA DE LOS SUPERMERCADOS

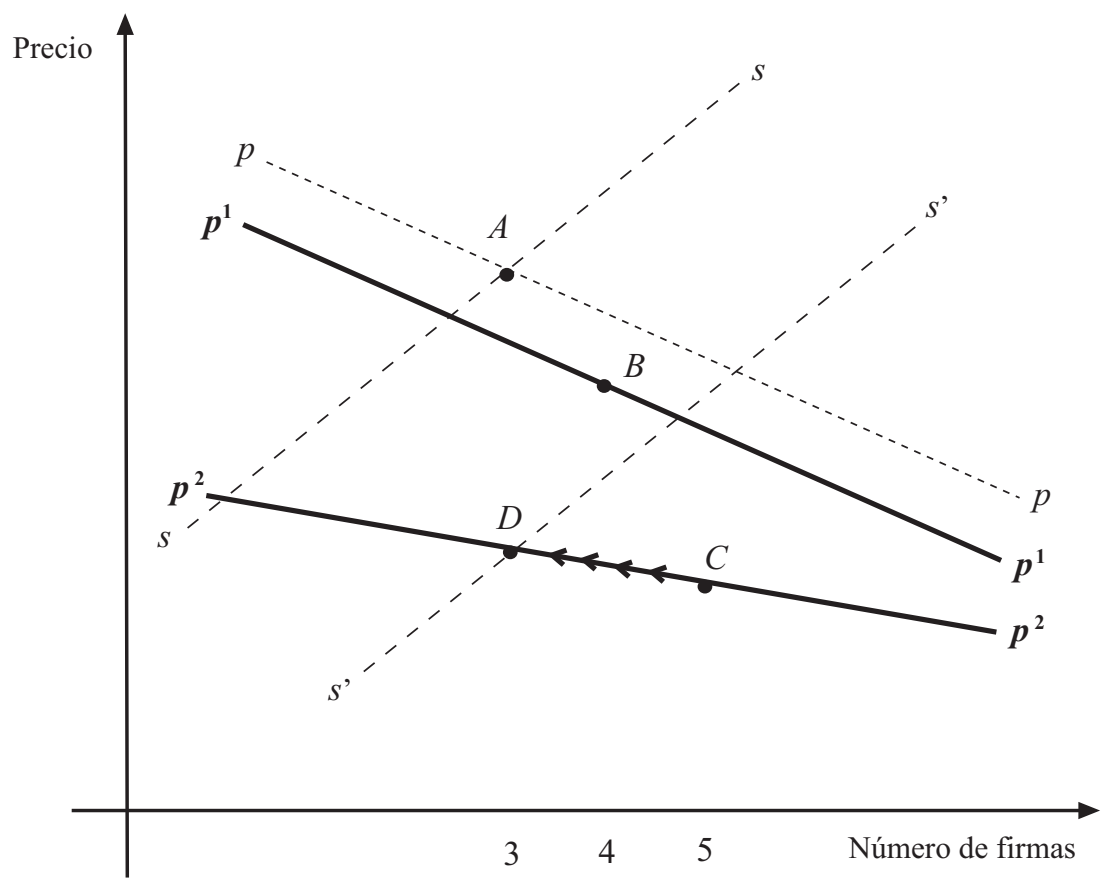


los precios iniciales. Sin embargo, desde el punto de vista del equilibrio de corto plazo el desplazamiento de la curva ss es irrelevante mientras no ocurra la entrada.

Segundo, con la aparición de la primera firma que tiene costos más bajos (ya sea porque entra o bien porque instala su centro de distribución), la curva $p p$ se desplaza hacia abajo hasta $p^{1} p^{1}$ —para cada número de firmas dado, el precio de equilibrio debiera ser más bajo- - Si la entrada aumenta el número de firmas (es decir, no ocurre por adquisición de una cadena existente o porque la cadena ya está presente, pero recién instala su centro de distribución), además habrá un desplazamiento a lo largo de la nueva curva, y el número de firmas aumentará de tres a cuatro hasta el punto $B$, lo que hará caer los precios aún más. De manera similar, la entrada de la segunda cadena debiera desplazar la curva $p p$ hacia abajo nuevamente hasta $p^{2} p^{2}$-la competencia en precios entre supermercados debiera ser más intensa si hay dos cadenas con centro de distribución que cuando hay una sola cadena- Si así ocurre, el efecto ya descrito vuelve a darse. Y si la entrada aumenta el número de firmas, el precio caerá aun más, y en el gráfico nos movemos a un punto tal como $C$.

El tercer efecto posible es que la entrada de competidores con costos marginales más bajos reduzca la pendiente de la curva $p p$ y atenúe la tradicional relación concentración-precio. Esto no es impensable, porque la nueva tecnología reduce los costos marginales y, por lo tanto, aumenta el margen precio-costo marginal a cada precio. Las regresiones que reportamos líneas abajo indican que esto ocurre con la aparición de la segunda cadena con centro de distribución nacional.

Por último, el Gráfico № 4 muestra el cuarto posible efecto del cambio estructural, a saber: que ocurra un ajuste con salida de firmas. Si la nueva curva ss es como s's' en el Gráfico $\mathrm{N}^{\circ} 4$, un punto como $C$ es insostenible en el largo plazo y algunas firmas saldrán ya sea por quiebra, cierre o adquisición. El precio entonces subirá, pero en el largo plazo será menor que el precio inicial en $D$.

De lo anterior se sigue que hay tres implicancias observables que se pueden testear.

Implicancia 1. Todo lo demás constante, el precio relativo de los alimentos en una ciudad dada cae cuando aparece una cadena con un centro de distribución nacional. 
Implicancia 2. Todo lo demás constante, el precio relativo de los alimentos en una ciudad dada cae aun más con la aparición de la segunda cadena con un centro de distribución nacional.

Implicancia 3. Todo lo demás constante, la presencia de una o dos cadenas con centro de distribución atenúa la relación concentración-precio.

En lo que sigue testearemos estas tres implicancias.

\subsection{Posibles sesgos}

No observables. Antes de seguir, es conveniente discutir sobre el posible sesgo de simultaneidad al estimar la relación entre concentración y precio. Se sabe que la estimación con datos de sección cruzada y mínimos cuadrados ordinarios dará por resultado un coeficiente sesgado cuando existan no observables que afectan simultáneamente al precio y la concentración (véase, por ejemplo, Bresnahan, 1989). En particular, cuando la concentración se mide mediante el coeficiente de Herfindahl de las ventas, los cambios de precio también la afectan. Evans et al. (1993) y Singh y Zhu (2006) proponen métodos para corregir ese sesgo. En nuestro caso, además de usar un índice Herfindahl construido con la participación en el número total de cajas, corregiremos por efectos fijos, lo que debiera ser suficiente para evitar este sesgo.

Simultaneidad de concentración y precio. De acuerdo con nuestro modelo, en el largo plazo la concentración y el precio relativo de los alimentos son variables endógenas determinadas por parámetros estructurales que las afectan simultáneamente a ambas. ¿No impide esto estimar la relación concentración-precio?

Como ya se dijo líneas arriba, desde el punto de vista econométrico las variaciones de la concentración en el corto plazo son exógenas, porque sólo compiten las firmas que ya están dentro del mercado. Por eso, en tanto no haya entrada, la posición de la curva ss es irrelevante -el equilibrio de corto plazo ocurre sobre la curva $p p$-.

Más aun, el hecho de que la curva ss se desplace a consecuencia de la entrada de los centros de distribución, pero que, por las razones que sean, la entrada tome más tiempo en algunas ciudades que en 
otras, es una oportunidad desde el punto de vista de la estimación. En efecto, la variación temporal de la aparición de cadenas con centro de distribución nacional es la que permite estimar el efecto del cambio estructural sobre la relación concentración-precio.

Cambio estructural y sesgo por variables omitidas. La tercera fuente de sesgos ocurre cuando se estima la relación concentraciónprecio sin controlar por las consecuencias del cambio estructural que revisamos líneas arriba. El Gráfico № 5 es una reproducción del Gráfico $\mathrm{N}^{\circ} 4$, pero con la tonalidad de las curvas pp y ss atenuada. Se aprecia en el gráfico que una regresión que no controle por el cambio estructural les ajustará una recta a los puntos $A, B, C$ y $D$ y, tal como se ve en el gráfico, sobrestimará la pendiente de la curva $p p$. En otras palabras, si se omite el cambio estructural, la regresión fuerza a la pendiente de la curva $p p$ a capturar estos efectos. Veremos líneas abajo que en el caso que nos ocupa la magnitud del sesgo es considerable.

GRÁFICO N ${ }^{\circ}$ 5: $\quad$ EL SESGO POR OMISIÓN DE VARIABLES CUANDO HAY CAMBIO ESTRUCTURAL

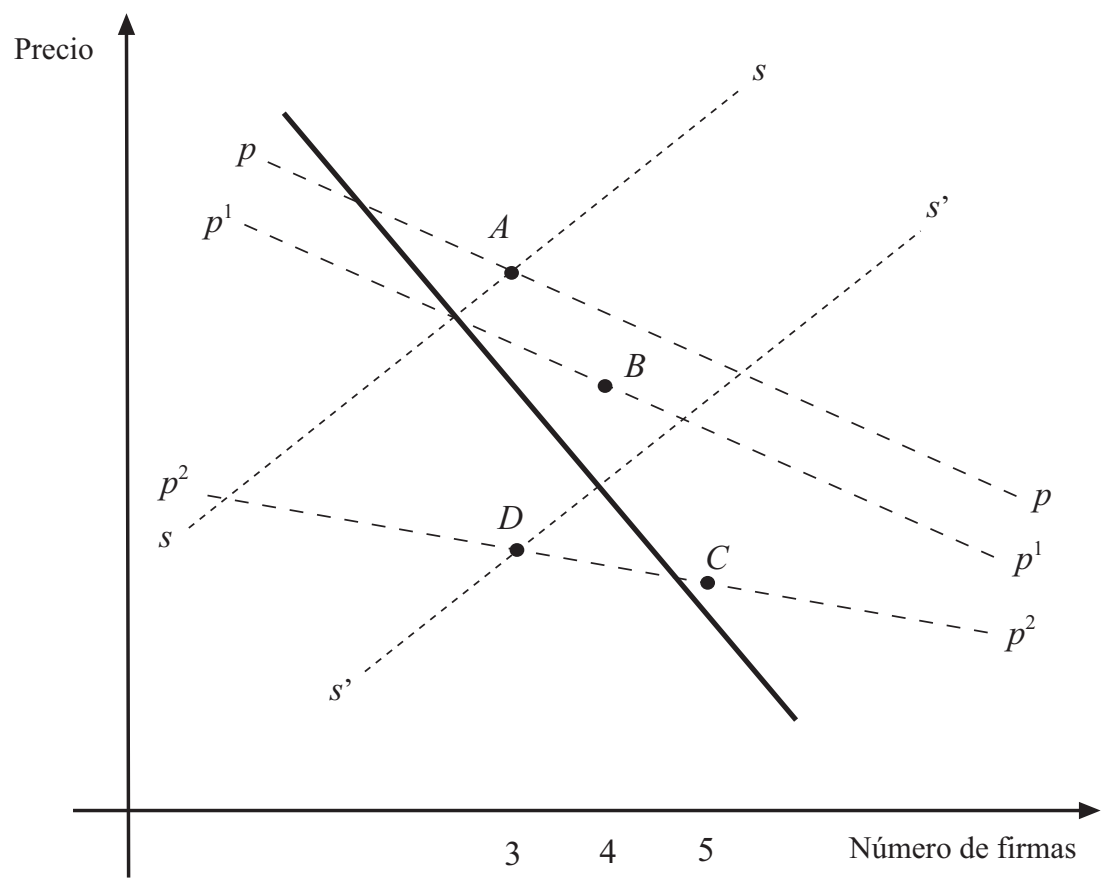




\section{ESTIMACIÓN Y RESULTADOS}

En esta sección estimamos un panel que permite testear las tres implicancias observables. Para eso necesitamos información sobre el precio de los alimentos en cada ciudad, la concentración y la presencia de tiendas de cadenas con centro de distribución nacional. Describimos los datos a continuación.

\subsection{Datos}

Salvo los datos de fecha de aparición de tiendas de cadena con centro de distribución, todos los restantes nos fueron gentilmente facilitados por Andrés Gómez-Lobo y Aldo González (a través del Honorable Tribunal de Defensa de la Libre Competencia), y corresponden a los que utilizaron para estimar su panel en 2007.

\subsubsection{Precios y concentración}

El precio relativo de los alimentos. Los datos de precios por ciudad se obtuvieron del Anuario de precios del Instituto Nacional de Estadísticas. El Anuario incluye precios mensuales de 95 productos alimenticios en 24 ciudades de Chile entre enero de 1998 y marzo de 2006. Gómez-Lobo y González (2007) siguieron a Lira et al. (2007) e incluyeron en su base de datos sólo 52 productos comercializados por supermercados, aquellos con precios reportados durante todo el período. Nosotros hacemos lo mismo.

El precio relativo de los alimentos, la variable dependiente en las regresiones, es el índice de precios de estos 52 productos deflactados por el IPC, es decir

$$
p_{i, t} \equiv \frac{P_{i, t}}{\mathrm{IPC}_{t}},
$$

donde $P_{i, t}$ es el valor de la canasta en la ciudad $i$ durante el mes $t$ e IPC $t$ es el índice de precios al consumidor durante el mes $t$. 
La medida de concentración. Para el análisis estadístico de la relación concentración-precio, utilizaremos el número equivalente de firmas (NEF), definido como el inverso del índice de Herfindahl-Hirschman, es decir

$$
\mathrm{NEF}_{i}=\frac{1}{\mathcal{H}_{i}},
$$

con $\mathcal{H}_{i}=\sum_{j=1}^{N} s_{i, j}^{2}$ y $s_{i, j}$ es la participación del supermercado $j$ en la ciudad $i$. La participación de mercado de cada cadena de supermercados se mide con la participación en el número total de cajas. Usamos el número equivalente de firmas porque así es más fácil interpretar económicamente el coeficiente estimado de la relación concentración-precio.

\subsubsection{Describiendo los datos}

El Cuadro $\mathrm{N}^{\circ} 3$ muestra los estadísticos descriptivos del precio relativo de los alimentos y de la concentración. El precio relativo promedio de la canasta de alimentos es 115,06, con un mínimo de 95,18 y un máximo de 150,61. Por su parte, el promedio del número equivalente de firmas en las 24 ciudades es 3,87, con un mínimo de una firma y un máximo de 7,75.

Evolución de la concentración. Antes de las regresiones es interesante examinar la evolución del precio relativo de los alimentos y de la concentración entre 1998 y 2006. La última línea del Cuadro № 4 muestra que en promedio la concentración no ha variado mayormente dentro de cada ciudad —la media anual del número equivalente de

CUADRO No 3: $\quad$ ESTADÍSTICOS DESCRIPTIVOS

\begin{tabular}{lrrrr}
\hline & Media & $\begin{array}{c}\text { Desviación } \\
\text { estándar }\end{array}$ & Mínimo & Máximo \\
\hline & & & & \\
Índice de Herfindahl - Hirschman & 3.145 & 1.655 & 1.290 & 10.000 \\
$\begin{array}{l}\text { Número equivalente de firmas (NEF) } \\
\text { Precio relativo de alimentos }\end{array}$ & 3,87 & 1,51 & 1 & 7,75 \\
& 115,06 & 8,00 & 95,18 & 150,61 \\
\hline
\end{tabular}

Nota: En todos los casos $n=1.192$. 
CUADRO N 4: $\quad$ EVOLUCIÓN DEL NÚMERO EQUIVALENTE DE FIRMAS

(media anual)

199819992000200120022003200420052006

\begin{tabular}{lrrrrrrrrll}
\hline Antofagasta & 2,0 & 2,9 & 2,9 & 3,0 & 3,0 & 2,8 & 2,8 & 2,9 & 3,2 & Antofagasta \\
Arica & 3,2 & 3,5 & 3,5 & 3,5 & 3,5 & 3,3 & 2,0 & 2,0 & 2,0 & Arica \\
Chillán & 4,2 & 4,2 & 4,2 & 4,2 & 4,2 & 4,2 & 4,2 & 3,1 & 3,0 & Chillán \\
Coihaique & 2,0 & 2,0 & 2,0 & 2,0 & 2,0 & 2,0 & 2,0 & 1,6 & 2,0 & Coihaique \\
Concepción & 5,7 & 5,7 & 5,7 & 5,7 & 5,7 & 5,7 & 5,0 & 4,8 & 4,8 & Concepción \\
Copiapó & 2,2 & 2,5 & 2,5 & 2,8 & 2,9 & 2,9 & 1,4 & 1,2 & 2,4 & Copiapó \\
Curicó & - & - & - & - & 3,1 & 3,1 & 4,7 & 4,7 & 4,7 & Curicó \\
Iquique & 3,6 & 3,7 & 3,7 & 3,7 & 3,7 & 3,6 & 3,4 & 3,4 & 3,4 & Iquique \\
La Serena & 2,8 & 2,8 & 2,8 & 2,7 & 2,8 & 2,7 & 2,4 & 2,4 & 3,0 & La Serena \\
Linares & - & - & - & - & 2,2 & 1,9 & 1,7 & 1,7 & 1,9 & Linares \\
Los Andes & - & - & - & - & 4,5 & 4,5 & 4,6 & 5,2 & 5,2 & Los Andes \\
Los Ángeles & - & - & - & - & 5,7 & 5,5 & 4,2 & 3,8 & 3,5 & Los Ángeles \\
Osorno & 3,8 & 3,8 & 3,7 & 3,4 & 3,2 & 4,3 & 4,3 & 4,3 & 4,3 & Osorno \\
Puerto Montt & - & - & - & - & 4,3 & 4,4 & 4,2 & 4,1 & 4,0 & Puerto Montt \\
Punta Arenas & 6,6 & 6,6 & 6,9 & 6,7 & 6,4 & 6,7 & 6,7 & 7,2 & 7,7 & Punta Arenas \\
Quillota & - & - & - & - & 2,6 & 2,6 & 2,7 & 4,3 & 4,3 & Quillota \\
Rancagua & 4,4 & 4,4 & 5,1 & 5,2 & 5,2 & 4,6 & 3,7 & 3,8 & 4,3 & Rancagua \\
San Antonio & - & - & - & - & 1,7 & 1,5 & 1,5 & 2,2 & 2,2 & San Antonio \\
Santiago & 5,7 & 5,4 & 5,6 & 5,8 & 6,1 & 6,1 & 4,7 & 4,4 & 4,4 & Santiago \\
San Fernando & - & - & - & - & 6,7 & 6,6 & 6,6 & 6,6 & 6,6 & San Fernando \\
Talca & 2,7 & 3,5 & 3,6 & 4,3 & 4,1 & 4,1 & 5,1 & 5,7 & 4,8 & Talca \\
Temuco & 5,4 & 5,4 & 5,4 & 5,4 & 5,2 & 5,3 & 5,0 & 4,7 & 4,6 & Temuco \\
Valdivia & 3,6 & 3,7 & 3,9 & 4,1 & 5,1 & 5,3 & 5,2 & 5,1 & 5,1 & Valdivia \\
Valparaíso & 1,3 & 1,3 & 1,3 & 1,3 & 1,3 & 1,4 & 2,2 & 2,2 & 2,1 & Valparaíso \\
Media simple & 3,7 & 3,8 & 3,9 & 4,0 & 4,0 & 4,0 & 3,8 & 3,8 & 3,9 & Media simple \\
& & & & & & & & & & \\
\hline & & & & & & & & & & \\
\hline
\end{tabular}

firmas se mueve entre 3,7 y 4,0—. Esta impresión se confirma mirando la evolución del número equivalente de firmas ciudad por ciudad. En algunas el número de firmas cae un tanto, en otras aumenta, pero la mayoría de los cambios es del orden de una firma equivalente.

Para testear formalmente la hipótesis de que la concentración no ha aumentado entre 1998 y 2006 hicimos un test de Kruskal-Wallis para el número equivalente de firmas $(\mathrm{NEF})^{25}$. La hipótesis nula es que

${ }^{25}$ El test no paramétrico de Kruskal-Wallis es una alternativa al test paramétrico Anova. Se usa para testear la hipótesis de que las materializaciones de una determinada variable aleatoria correspondientes a $k$ muestras diferentes provienen del mismo modelo poblacional. Se trata de un test que está libre de la distribución en el sentido de que su distribución bajo la hipótesis nula no depende de la especificación completa de la función de distribución de probabilidad de la población de la cual fueron obtenidas las observaciones. Es, por ende, válido bajo supuestos bastante generales respecto de la población subyacente. El único requisito es que las muestras sean aleatorias. No exige las condiciones de homocedasticidad y normalidad necesarias para que se pueda aplicar Anova. 
múltiples muestras (en este caso las nueve muestras anuales de, según sea al año, 16 ó 24) fueron generadas por el mismo modelo poblacional. Bajo la hipótesis nula, las diferentes muestras tienen, por ende, idénticas medianas. Los resultados de este test se reportan en el Cuadro $\mathrm{N}^{\circ}$ A1 del Apéndice.

El test reportado en el Cuadro $\mathrm{N}^{\circ}$ A1 indica que la mediana del número equivalente de firmas es la misma para cada año de la muestra. Tal como puede observarse, el estadígrafo $\chi^{2}$ alcanza un valor de 0,974 . Para ocho grados de libertad, el valor del estadístico $p$ asociado es 0,9984 , por lo que no es posible rechazar la hipótesis nula a ningún nivel estándar de significancia estadística.

En conclusión, y al contrario de lo que se podría creer a partir del aumento considerable de la concentración de las ventas de supermercado a nivel nacional, aguas abajo no han ocurrido grandes variaciones de la concentración. La explicación, por supuesto, es que las mismas dos cadenas (D\&S y Cencosud) han ido ingresando progresivamente en las ciudades de Chile, pero en cada una de éstas otras cadenas locales han mantenido su participación.

Evolución del precio relativo. El Cuadro $\mathrm{N}^{\circ} 5$ muestra la evolución del precio relativo de los alimentos entre 1998 y 2006 en cada ciudad. La última línea muestra que el promedio simple anual cae fuertemente entre 1998 y 1999, continúa cayendo hasta 2002 y luego aumenta un tanto en 2005 y $2006^{26}$. La caída del precio relativo también es aparente en ciudad por ciudad, especialmente entre 1998 y 1999.

Para testear formalmente la hipótesis de que el precio relativo cambió entre 1998 y 2006 también hicimos un test de Kruskal-Wallis para el precio relativo de los alimentos. Los resultados se presentan en el Apéndice A, Cuadro $\mathrm{N}^{\circ}$ A2.

La hipótesis nula es que la distribución del precio promedio de la canasta es la misma para todos los años. Esta vez, sin embargo, la hipótesis nula se rechaza, pues el estadígrafo de $\chi^{2}$ alcanza un valor de 61,998. Para ocho grados de libertad, el estadístico $p$ es cercano a 0,0001 . De esta forma, es posible rechazar la hipótesis nula a cualquier nivel estándar de significancia. Más aún, la diferencia de precios entre 1998 y 2006 resulta estadísticamente distinta de cero al 0,2\%.

${ }^{26}$ Nótese que el promedio “anual” de 2006 se calcula con datos hasta marzo. 
$\begin{array}{ll}\text { CUADRO N } & \text { 5: } \\ \text { EVOLUCIÓN DEL PRECIO REAL DE LA CANASTA } \\ \text { (media anual) }\end{array}$

\begin{tabular}{|c|c|c|c|c|c|c|c|c|c|c|}
\hline & 1998 & 1999 & 2000 & 2001 & 2002 & 2003 & 2004 & 2005 & 2006 & \\
\hline Antofagasta & 144,1 & 120,4 & 116,9 & 111,3 & 113,9 & 118,2 & 117,8 & 120,2 & 122,0 & Antofagasta \\
\hline Arica & 128,4 & 116,0 & 114,9 & 111,3 & 112,5 & 114,1 & 110,9 & 115,9 & 122,1 & Arica \\
\hline Chillán & 126,4 & 113,0 & 110,9 & 105,8 & 105,6 & 105,6 & 107,3 & 108,4 & 113,9 & Chillán \\
\hline Coihaique & 127,7 & 122,6 & 126,1 & 124,1 & 131,7 & 135,0 & 134,4 & 132,9 & 129,7 & Coihaique \\
\hline Concepción & 126,8 & 114,0 & 109,0 & 107,6 & 110,2 & 107,5 & 108,9 & 114,1 & 118,2 & Concepción \\
\hline Copiapó & 133,1 & 117,6 & 118,6 & 115,1 & 116,4 & 119,9 & 120,3 & 126,0 & 121,0 & Copiapó \\
\hline Curicó & - & & - & - & 108,6 & 108,8 & 107,0 & 112,9 & 114,6 & Curicó \\
\hline Iquique & 137,8 & 121,9 & 116,5 & 112,8 & 115,7 & 113,2 & 111,8 & 113,4 & 119,1 & Iquique \\
\hline La Serena & 133,0 & 110,5 & 114,6 & 107,9 & 110,3 & 111,8 & 112,3 & 112,6 & 115,1 & La Serena \\
\hline Linares & - & - & - & - & 104,2 & 109,0 & 105,7 & 105,8 & 110,5 & Linares \\
\hline Los Andes & - & - & - & - & 111,6 & 110,3 & 108,8 & 107,4 & 112,8 & Los Andes \\
\hline Los Ángeles & - & - & - & - & 106,9 & 104,5 & 104,7 & 111,1 & 117,2 & Los Ángeles \\
\hline Osomo & - & - & - & - & 108,0 & 110,0 & 109,7 & 110,7 & 111,6 & Osomo \\
\hline Puerto Montt & 130,7 & 121,4 & 122,7 & 115,5 & 112,3 & 117,8 & 112,0 & 114,5 & 117,1 & Puerto Montt \\
\hline Punta Arenas & 127,1 & 114,0 & 119,2 & 126,5 & 110,6 & 109,2 & 119,7 & 121,6 & 122,3 & Punta Arenas \\
\hline Quillota & - & - & - & - & 114,2 & 113,7 & 115,1 & 113,1 & 118,0 & Quillota \\
\hline Rancagua & 127,2 & 114,5 & 121,4 & 109,3 & 105,6 & 111,4 & 113,2 & 114,5 & 117,4 & Rancagua \\
\hline San Antonio & - & - & - & - & 110,7 & 112,2 & 113,7 & 111,9 & 116,7 & San Antonio \\
\hline Santiago & 115,7 & 117,1 & 115,3 & 113,5 & 113,2 & 114,9 & 115,3 & 116,4 & 121,3 & Santiago \\
\hline San Fernando & - & - & - & - & 110,1 & 109,9 & 109,1 & 109,5 & 110,1 & San Fernando \\
\hline Talca & 118,1 & 106,0 & 109,8 & 102,6 & 106,1 & 112,2 & 111,8 & 114,8 & 119,3 & Talca \\
\hline Temuco & 119,4 & 110,1 & 113,6 & 110,9 & 112,1 & 114,7 & 108,9 & 110,1 & 117,2 & Temuco \\
\hline Valdivia & 131,7 & 121,7 & 115,9 & 107,3 & 104,0 & 103,3 & 103,4 & 105,5 & 109,6 & Valdivia \\
\hline Valparaíso & 131,6 & 123,9 & 120,8 & 117,1 & 117,9 & 114,2 & 112,1 & 113,7 & 118,1 & Valparaíso \\
\hline Media simple & 128,7 & 116,5 & 116,6 & 112,4 & 111,3 & 112,6 & 112,2 & 114,0 & 117,3 & Media simple \\
\hline
\end{tabular}

La presencia de cadenas con un centro de distribución nacional. La última variable considerada es el año en que aparecen en cada ciudad tiendas de supermercado cuyo dueño es una cadena con un centro de distribución nacional. Cencosud nos proporcionó la fecha de inauguración de tiendas Jumbo y Santa Isabel. La información sobre presencia de tiendas de supermercado de D\&S (Almac, Ekono y Líder) nos fue parcialmente proporcionada por Cencosud y completada con información proporcionada por D\&S en sus reportes trimestrales y la Form 20F de la Securities and Exchange Commission de los Estados Unidos $^{27}$.

${ }^{27}$ Disponibles en www.dys.cl. 
La información sobre presencia de cadenas con un centro de distribución nacional se resume en el Cuadro $\mathrm{N}^{\circ} 6$. Nótese que en la mayoría de las ciudades el número de cadenas con centro de distribución nacional aumenta en el año 2000. Esto ocurre porque ese año se inauguró el centro de distribución de Santa Isabel, cadena que sería adquirida por Cencosud en 2003. El centro de distribución de D\&S se inauguró a fines de 1997.

CUADRO N 6: $\quad$ EVOLUCIÓN DEL NÚMERO DE CADENAS CON CENTRO DE DISTRIBUCIÓN NACIONAL EN CADA CIUDAD

199819992000200120022003200420052006

$\begin{array}{lllllllllll}\text { Antofagasta } & 1 & 1 & 2 & 2 & 2 & 2 & 2 & 2 & 2 & \text { Antofagasta } \\ \text { Arica } & 1 & 1 & 2 & 2 & 2 & 2 & 2 & 2 & 2 & \text { Arica } \\ \text { Chillán } & - & - & 1 & 1 & 1 & 1 & 1 & 1 & 1 & \text { Chillán } \\ \text { Coihaique } & - & - & - & - & - & - & - & - & - & \text { Coihaique } \\ \text { Concepción } & 1 & 1 & 2 & 2 & 2 & 2 & 2 & 2 & 2 & \text { Concepción } \\ \text { Copiapó } & - & - & - & - & - & - & - & 1 & 2 & \text { Copiapó } \\ \text { Curicó } & - & - & 1 & 1 & 1 & 2 & 2 & 2 & 2 & \text { Curicó } \\ \text { Iquique } & 1 & 1 & 2 & 2 & 2 & 2 & 2 & 2 & 2 & \text { Iquique } \\ \text { La Serena } & 1 & 1 & 2 & 2 & 2 & 2 & 2 & 2 & 2 & \text { La Serena } \\ \text { Linares } & - & - & 1 & 1 & 1 & 1 & 1 & 1 & 2 & \text { Linares } \\ \text { Los Andes } & - & - & 1 & 1 & 1 & 1 & 1 & 1 & 2 & \text { Los Andes } \\ \text { Los Ángeles } & - & - & 1 & 1 & 2 & 2 & 2 & 2 & 2 & \text { Los Ángeles }\end{array}$

199819992000200120022003200420052006

$\begin{array}{lllllllllll}\text { Osorno } & 1 & 1 & 1 & 2 & 2 & 2 & 2 & 2 & 2 & \text { Osorno } \\ \text { Puerto Montt } & - & - & 1 & 1 & 2 & 2 & 2 & 2 & 2 & \text { Puerto Montt } \\ \text { Punta Arenas } & - & - & - & - & - & - & 1 & 1 & 1 & \text { Punta Arenas } \\ \text { Quillota } & - & - & 1 & 1 & 1 & 1 & 2 & 2 & 2 & \text { Quillota } \\ \text { Rancagua } & 1 & 1 & 2 & 2 & 2 & 2 & 2 & 2 & 2 & \text { Rancagua } \\ \text { San Antonio } & - & - & - & - & - & - & - & - & - & \text { San Antonio } \\ \text { Santiago } & 1 & 1 & 2 & 2 & 2 & 2 & 2 & 2 & 2 & \text { Santiago } \\ \text { San Fernando } & - & - & - & 1 & 1 & 1 & 1 & 1 & 1 & \text { San Fernando } \\ \text { Talca } & 1 & 1 & 2 & 2 & 2 & 2 & 2 & 2 & 2 & \text { Talca } \\ \text { Temuco } & 1 & 1 & 2 & 2 & 2 & 2 & 2 & 2 & 2 & \text { Temuco } \\ \text { Valdivia } & - & - & 1 & 1 & 2 & 2 & 2 & 2 & 2 & \text { Valdivia } \\ \text { Valparaíso } & 1 & 1 & 2 & 2 & 2 & 2 & 2 & 2 & 2 & \text { Valparaíso }\end{array}$

Fuente: Cencosud. 


\subsection{Estimación y resultados}

\subsubsection{La ecuación a estimar}

Nuestra estimación es un testeo de las implicancias observables de la aparición de cadenas con centro de distribución nacional, suponiendo que sus costos marginales son más bajos. Tal como se vio líneas arriba, esto implica que la competencia en precios se intensifica. La curva $p p$ se desplaza hacia abajo y posiblemente se aplana.

Para testear estas implicancias estimaremos la siguiente ecuación de regresión:

$$
\begin{aligned}
p_{i, t} & =\alpha+\beta \times \mathrm{NEF}_{i, t} \\
& +\gamma_{1} \times D_{i, t}^{1}+\gamma_{2} \times D_{i, t}^{2} \\
& +\delta_{1} \times\left(D_{i, t}^{1} \cdot \mathrm{NEF}_{i, t}\right)+\delta_{2} \times\left(D_{i, t}^{2} \cdot \mathrm{NEF}_{i, t}\right) \\
& +\zeta_{i}+n_{t}+\varepsilon_{i, t^{\circ}}
\end{aligned}
$$

$D_{i, t}^{1}$ es una dummy que toma el valor 1 desde el momento en que aparece la primera tienda de una cadena con un centro de distribución nacional en la ciudad $i$ y cero para fechas anteriores ${ }^{28}$. La magnitud del efecto sobre el precio relativo de los alimentos —el desplazamiento hacia abajo de la curva $p p$ —es capturada por el coeficiente $\gamma_{1}$, el que debería ser menor que cero si nuestra tesis es correcta.

De manera similar, $D_{i, t}^{2}$ es una dummy que toma el valor de 1 a partir de la aparición de la segunda tienda de una cadena con un centro de distribución nacional en la ciudad $i$ y cero para fechas anteriores. La magnitud del efecto sobre el precio relativo de los alimentos —la caída adicional de la curva $p p$ — es capturada por el coeficiente $\gamma_{2}$.

De particular interés son los coeficientes $\delta_{1}$ y $\delta_{2}$, que capturan la interacción entre el número equivalente de firmas y la aparición de tiendas de cadenas con centro de distribución nacional, las dummies $D_{i, t}^{1}$ y $D_{i, t}^{2}$. Nótese que

$$
\frac{\partial E\left(p_{i, t}\right)}{\partial \mathrm{NEF}_{i, t}}=\beta+\delta_{1} \times D_{i, t}^{1}+\delta_{2} \times D_{i, t}^{2} .
$$

${ }^{28}$ Como ya se dijo, la "aparición” puede ocurrir porque una cadena que ya cuenta con un centro de distribución instala su primera tienda en la ciudad; porque una cadena que ya tiene centro de distribución nacional adquiere una cadena que no lo tiene; o bien porque una cadena que ya está en una ciudad dada comienza a operar un centro de distribución nacional. 
Claramente $\beta<0$ —ésta es la tradicional relación concentraciónprecio- - Si la aparición en una ciudad de una o dos cadenas con centro de distribución nacional atenúa esa relación acercándola a la que se observaría en competencia perfecta, los coeficientes $\delta_{1}$ y $\delta_{2}$ deberían ser positivos.

\subsubsection{Resultado de la estimación}

La ecuación (4.1) se estimó con datos mensuales y trimestrales. Las variables trimestrales son promedios simples de las mensuales. Dadas las características de la muestra y la frecuencia de los datos, la estimación por efectos fijos intragrupos entrega estimadores consistentes y eficientes, por lo que calculamos la ecuación (4.1) por mínimos cuadrados del modelo intragrupos ${ }^{29}$.

El Cuadro $N^{\circ} 7$ reporta la estimación de la ecuación (4.1) incluyendo a las 24 ciudades, mientras que el Cuadro $\mathrm{N}^{\circ} 8$ reporta la estimación que excluye a Santiago ${ }^{30}$.

En cada caso, la columna 1 reporta la regresión sin controlar por los efectos de la presencia de cadenas con centro de distribución. En cada caso, también, se reporta una regresión que no incluye los términos de interacción —éstas se reportan en las columnas pares (en cada caso 2, 4 y 6)-.

De un examen rápido de los Cuadros $\mathrm{N}^{\circ} 7$ y $\mathrm{N}^{\circ} 8$ se concluye que las estimaciones son estables, independientes de la periodicidad de los

${ }^{29}$ Los estimadores de efecto fijo corresponden a los de mínimos cuadrados ordinarios del modelo intragrupos y tienen las mismas propiedades. En particular, bajo los supuestos de regresores estrictamente estacionarios y de errores y regresores exógenos, $\beta_{\text {ef }}$ converge en probabilidad a $\beta_{0}$, el verdadero vector de parámetros poblaciones. Otra forma de ver esto es notando que los estimadores de efecto fijo son idénticos a los que se obtienen al usar LSDV (por least square dummy variable regression), que estima con mínimos cuadrados ordinarios utilizando una dummy para cada $\zeta_{i}$.

${ }^{30}$ La razón que podría justificar excluir a Santiago es que por su tamaño (alrededor de 70.000 ha) podría contener más de un "mercado". Como se puede ver en el Cuadro 3.3a en Galetovic y Sanhueza (2006), la segunda ciudad más grande de Chile es el Gran Valparaíso, que incluye a Valparaíso, Viña del Mar, Quilpué, Villa Alemana y Concón, que cubre apenas 10.669 ha.

Al mismo tiempo, es claro que una de las razones que justifican incluir a Santiago es que la aparición de cadenas con centro de distribución ocurrió en toda la ciudad más o menos al mismo tiempo. Por lo tanto, su inclusión da información adicional sobre el efecto en el precio relativo de los alimentos de las cadenas con un centro de distribución nacional. 
CUADRO No $7: \quad$ REGRESIONES CON SANTIAGO

\begin{tabular}{|c|c|c|c|c|c|c|}
\hline \multirow[t]{2}{*}{ Variable } & \multicolumn{3}{|c|}{ Datos mensuales } & \multicolumn{3}{|c|}{ Datos trimestrales } \\
\hline & (1) & (2) & (3) & (4) & (5) & (6) \\
\hline NEF & $\begin{array}{l}-1,42 \\
(0,20) \\
{[0,000]}\end{array}$ & $\begin{array}{l}-0,82 \\
(0,20) \\
{[0,000]}\end{array}$ & $\begin{array}{l}-3,15 \\
(0,29) \\
{[0,000]}\end{array}$ & $\begin{array}{l}-1,68 \\
(0,40) \\
{[0,000]}\end{array}$ & $\begin{array}{l}-0,87 \\
(0,39) \\
{[0,003]}\end{array}$ & $\begin{array}{l}-3,24 \\
(0,74) \\
{[0,000]}\end{array}$ \\
\hline $\mathrm{D}^{1}$ & & $\begin{array}{l}-3,73 \\
(0,52) \\
{[0,000]}\end{array}$ & $\begin{array}{c}-10,44 \\
(1,39) \\
{[0,087]}\end{array}$ & & $\begin{array}{l}-5,17 \\
(0,97) \\
{[0,000]}\end{array}$ & $\begin{array}{c}-12,41 \\
(2,72) \\
{[0,000]}\end{array}$ \\
\hline $\mathrm{D}^{2}$ & & $\begin{array}{l}-4,72 \\
(0,43) \\
{[0,000]}\end{array}$ & $\begin{array}{c}-10,00 \\
(0,86) \\
{[0,000]}\end{array}$ & & $\begin{array}{l}-5,87 \\
(0,79) \\
{[0,000]}\end{array}$ & $\begin{array}{c}-10,48 \\
(1,68) \\
{[0,000]}\end{array}$ \\
\hline $\mathrm{D}^{1} \times \mathrm{NEF}$ & & & $\begin{array}{l}1,47 \\
(0,29) \\
{[0,000]}\end{array}$ & & & $\begin{array}{l}1,59 \\
(0,58) \\
{[0,006]}\end{array}$ \\
\hline $\mathrm{D}^{2} \times \mathrm{NEF}$ & & & $\begin{array}{c}1,40 \\
(00,20) \\
{[0,000]}\end{array}$ & & & $\begin{array}{c}1,21 \\
(00,38) \\
{[0,002]}\end{array}$ \\
\hline$n$ & 986 & 986 & 986 & 663 & 663 & 663 \\
\hline $\mathrm{R}^{2}$ within & 0,55 & 0,58 & 0,60 & 0,39 & 0,46 & 0,48 \\
\hline $\mathrm{R}^{2}$ between & 0,30 & 0,25 & 0,20 & 0,01 & 0,16 & 0,16 \\
\hline $\mathrm{R}^{2}$ overall & 0,45 & 0,47 & 0,44 & 0,23 & 0,35 & 0,32 \\
\hline $\begin{array}{l}\text { Test de Wald } \\
H_{0}: \beta+\delta_{1}+ \\
F\end{array}$ & & & 1,77 & & & 1,07 \\
\hline Estadístico $p$ & & & {$[0,184]$} & & & {$[0,300]$} \\
\hline
\end{tabular}

Notas: (Desviación estándar en paréntesis.)

[Estadístico $p$ en corchetes.]

datos o de si se incluye o excluye a Santiago. El coeficiente estimado del número equivalente de firmas $(\hat{\beta})$ es negativo y significativo a cualquier nivel estándar de significancia, resultado que no debiera sorprender ${ }^{31-32}$.

${ }^{31}$ Nótese que la estimación controla por posibles cambios estructurales y por efectos fijos por ciudad y temporales. Por lo tanto, el coeficiente estimado $\beta$ es un estimador insesgado de la pendiente de la curva $p p$.

${ }^{32}$ Un test de Hausman indica que es apropiado estimar el modelo mensual con efectos aleatorios, tanto con Santiago $\left(\chi^{2}=25,53, p=1,000\right)$ como sin Santiago $\left(\chi^{2}=\right.$ $26,81, p=1,000$ ). El Cuadro $N^{\circ}$ A3 en el Apéndice compara las regresiones mensuales con efectos fijos y aleatorios. Los resultados son casi idénticos.

El mismo test de Hausman indica que el modelo de efectos fijos es apropiado si se trata de la estimación con datos trimestrales, tanto con Santiago $\left(\chi^{2}=267,66\right.$, $p=0,000)$ como sin Santiago $\left(\chi^{2}=138,56, p=0,000\right)$. 
CUADRO No 8: $\quad$ REGRESIONES SIN SANTIAGO

\begin{tabular}{|c|c|c|c|c|c|c|}
\hline \multirow[t]{2}{*}{ Variable } & \multicolumn{3}{|c|}{ Datos mensuales } & \multicolumn{3}{|c|}{ Datos trimestrales } \\
\hline & (1) & (2) & (3) & (4) & (5) & (6) \\
\hline NEF & $\begin{array}{l}-1,33 \\
(0,20) \\
{[0,000]}\end{array}$ & $\begin{array}{l}-0,66 \\
(0,20) \\
{[0,001]}\end{array}$ & $\begin{array}{l}-2,67 \\
(0,38) \\
{[0,000]}\end{array}$ & $\begin{array}{l}-1,64 \\
(0,42) \\
{[0,000]}\end{array}$ & $\begin{array}{l}-0,76 \\
(0,41) \\
{[0,063]}\end{array}$ & $\begin{array}{l}-2,89 \\
(0,77) \\
{[0,000]}\end{array}$ \\
\hline $\mathrm{D}^{1}$ & & $\begin{array}{l}-3,44 \\
(0,51) \\
{[0,000]}\end{array}$ & $\begin{array}{l}-9,98 \\
(1,39) \\
{[0,000]}\end{array}$ & & $\begin{array}{l}-5,00 \\
(0,99) \\
{[0,000]}\end{array}$ & $\begin{array}{c}-12,12 \\
(2,77) \\
{[0,000]}\end{array}$ \\
\hline $\mathrm{D}^{2}$ & & $\begin{array}{l}-5,13 \\
(0,43) \\
{[0,000]}\end{array}$ & $\begin{array}{l}-8,48 \\
(0,90) \\
{[0,000]}\end{array}$ & & $\begin{array}{l}-6,25 \\
(0,81) \\
{[0,000]}\end{array}$ & $\begin{array}{l}-9,33 \\
(1,78) \\
{[0,000]}\end{array}$ \\
\hline $\mathrm{D}^{1} \times \mathrm{NEF}$ & & & $\begin{array}{l}1,44 \\
(0,29) \\
{[0,000]}\end{array}$ & & & $\begin{array}{l}1,57 \\
(0,59) \\
{[0,008]}\end{array}$ \\
\hline $\mathrm{D}^{2} \times \mathrm{NEF}$ & & & $\begin{array}{c}0,93 \\
(00,21) \\
{[0,000]}\end{array}$ & & & $\begin{array}{c}0,85 \\
(00,42) \\
{[0,079]}\end{array}$ \\
\hline$n$ & 1.887 & 1.887 & 1.887 & 630 & 630 & 630 \\
\hline $\mathrm{R}^{2}$ within & 0,55 & 0,61 & 0,62 & 0,40 & 0,48 & 0,49 \\
\hline $\mathrm{R}^{2}$ between & 0,30 & 0,25 & 0,22 & 0,01 & 0,16 & 0,17 \\
\hline $\mathrm{R}^{2}$ overall & 0,45 & 0,49 & 0,47 & 0,24 & 0,36 & 0,34 \\
\hline $\begin{array}{l}\text { Test de Wald } \\
H_{0}: \beta+\delta_{1}+\delta \\
F \\
\text { Estadístico } p\end{array}$ & & & $\begin{array}{c}2,01 \\
{[0,157]}\end{array}$ & & & $\begin{array}{c}1,11 \\
{[0,292]}\end{array}$ \\
\hline
\end{tabular}

Notas: (Desviación estándar en paréntesis.)

[Estadístico $p$ en corchetes.]

En vista de la estabilidad de las estimaciones, en adelante continuaremos discutiendo la regresión 6 del Cuadro $\mathrm{N}^{\circ} 7$, es decir aquella que incluye a Santiago y se estima con datos trimestrales. Elegimos esta regresión por tres razones.

Una es que la caída pronosticada del precio relativo de los alimentos es de orden de magnitud similar a la materializada a nivel nacional. Otra es que los datos trimestrales garantizan un período suficiente que permite descartar cualquier dependencia intertemporal del precio relativo de los alimentos, más allá de que tal relación no sea 
relevante dentro de los supermercados incluso mes a mes (véase la discusión en el Apéndice B, donde comentamos el trabajo de GómezLobo y González). Por último, el número de grados de libertad es más que suficiente.

Lo más novedoso de nuestros resultados son los coeficientes estimados de las variables dummy $D_{1}$ y $D_{2}\left(\gamma_{1}\right.$ y $\left.\gamma_{2}\right)$ y sus interacciones con el número equivalente de firmas $\left(\delta_{1}\right.$ y $\left.\delta_{2}\right)$.

Los coeficientes estimados $\hat{\gamma}_{1}$ y $\hat{\gamma}_{2}$ son negativos y altamente significativos. Esto confirma que, todo lo demás constante, la aparición en una ciudad de una cadena de supermercados con un centro de distribución nacional hace caer el precio de los alimentos, caída que aumenta con la aparición de la segunda cadena. Más aun, la alta significancia estadística de los tests $t$ resalta el sesgo generado por omisión de variables relevantes cuando se ignora este cambio estructural.

Nuestra regresión también permite cuantificar la magnitud del error que se comete cuando se ignora que la presencia de cadenas con centro de distribución nacional afecta la pendiente de la curva $p p$. De la regresión se puede apreciar que la presencia de la primera cadena con un centro de distribución nacional atenúa la relación concentraciónprecio: una vez que aparece la primera cadena, el coeficiente de NEF cae (en valor absoluto) desde $-3,24$ hasta $-1,65(=-3,24+1,59+1,21)$. El coeficiente $\hat{\delta}_{1}$ es significativamente distinto de cero a cualquier nivel de significancia estándar.

De manera similar, la aparición de la segunda cadena con un centro de distribución nacional atenúa la relación concentración-precio aun más: una vez que aparece la segunda cadena, el coeficiente de NEF cae en valor absoluto desde $-3,24$ hasta $-0,44(=-3,24+1,59+1,21)$. El coeficiente $\hat{\delta}_{2}$ también es significativamente distinto de cero a cualquier nivel de significancia estándar.

Más importante aun, un test de Wald indica que la hipótesis nula de que

$$
\beta+\delta_{1}+\delta_{2}=0
$$

(es decir que la curva $p p$ se aplana completamente con la aparición de la segunda cadena con un centro de distribución nacional) no se puede rechazar a los niveles estándares de confianza. Esto sugiere que D\&S y Cencosud imponen condiciones similares a las de competencia perfecta. 
El sesgo por omisión de variables. El sesgo por omisión de variables, que se explica en el Gráfico $\mathrm{N}^{0} 5$, se puede apreciar comparando la columna 4 (la regresión con datos trimestrales que no incluyen dummies) con la columna 6. En efecto, el coeficiente asociado a NEF $(\beta)$ se reduce en valor absoluto y pasa de $-1,68$ a $-0,44(=-3,24+$ $1,59+1,21$ ) en aquellas ciudades en que compiten dos cadenas con un centro de distribución nacional.

Más aun, la comparación entre la regresión 4 y la 5 indica que si se ignora el efecto de la aparición de la segunda cadena con un centro de distribución nacional sobre la pendiente de la curva $p p$, también se subestima el efecto directo de la aparición de la primera y de la segunda cadena. En efecto, al incluir las dummies de interacción, los coeficientes de las dummies de nivel $\left(\gamma_{1}\right.$ y $\left.\gamma_{2}\right)$ aumentan dramáticamente en valor absoluto: el coeficiente estimado para $D^{1}, \hat{\delta}_{1}$, pasa de $-5,17$ a $-12,41$ y sigue siendo significativamente distinto de cero a un nivel de significancia cercano al $2 \%$. El coeficiente asociado a $D^{2}, \hat{\delta}_{1}$ pasa de $-5,87$ a $-10,48$ y es significativo a cualquier nivel estándar de significancia.

\subsubsection{La magnitud económica de los coeficientes}

Para calibrar la magnitud económica de los coeficientes describimos a continuación los resultados de un par de ejercicios que se presentan en el Cuadro $\mathrm{N}^{\circ} 9$. Es conveniente recordar que la media del precio relativo de los alimentos es 115,06 . Así por ejemplo, y como el coeficiente estimado de NEF en la regresión 6 del Cuadro $\mathrm{N}^{\circ} 7$ es $-3,24$, se sigue que si el número equivalente de firmas cae en uno, los precios deberían aumentar en

$$
\frac{-3,24}{115,06} \times(-1) \approx 0,028
$$

ó 2,8\%. El ejercicio reportado en la columna 1 del Cuadro $\mathrm{N}^{\circ} 9$ usa la estimación con datos trimestrales incluyendo Santiago (la columna 6 del Cuadro $N^{\circ} 7$ ). La columna 2 ocupa la regresión con datos trimestrales, pero que excluye a Santiago. Se puede apreciar que los resultados son muy similares, por lo que comentaremos los de la regresión con Santiago. 
CUADRO N ${ }^{\circ}$ 9: CAMBIO PORCENTUAL DEL PRECIO RELATIVO DE LOS ALIMENTOS CUANDO APARECEN CADENAS CON CENTRO DE DISTRIBUCIÓN NACIONAL

\begin{tabular}{|c|c|c|}
\hline & $\begin{array}{l}\text { Regresión trimestral, } \\
\text { con Santiago }\end{array}$ & $\begin{array}{l}(2) \\
\text { Regresión trimestral, } \\
\text { sin Santiago }\end{array}$ \\
\hline $\begin{array}{l}\text { Una firma equivalente menos si no } \\
\text { hay ninguna cadena con centro de } \\
\text { distribución nacional }\end{array}$ & $2,8 \%$ & $2,5 \%$ \\
\hline $\begin{array}{l}\text { Una firma equivalente menos si hay } \\
\text { una cadena con centro de distribu- } \\
\text { ción nacional }\end{array}$ & $1,4 \%$ & $1,2 \%$ \\
\hline $\begin{array}{l}\text { Una firma equivalente menos si hay } \\
\text { dos cadenas con centro de distribu- } \\
\text { ción nacional }\end{array}$ & $0,4 \%$ & $0,4 \%$ \\
\hline $\begin{array}{l}\text { Aparición de la primera cadena, sin } \\
\text { variar el número de firmas equiva- } \\
\text { lentes }\end{array}$ & $-10,8 \%$ & $-10,5 \%$ \\
\hline $\begin{array}{l}\text { Aparición de la segunda cadena, sin } \\
\text { variar el número de firmas (efecto } \\
\text { total, } \delta_{1}+\delta_{2} \text { ) }\end{array}$ & $-20,9 \%$ & $-18,6 \%$ \\
\hline $\begin{array}{l}\text { Dos cadenas y dos firmas menos } \\
\text { (efecto total, } 1+2 \text { ) }\end{array}$ & $-20,1 \%$ & $-17,8 \%$ \\
\hline
\end{tabular}

Nota: Todos los efectos han sido evaluados a la media muestral del precio relativo de los alimentos, 115,06.

Primer ejercicio: precios y cadenas con centro de distribución. La columna 1 del Cuadro $\mathrm{N}^{\circ} 9$ muestra el efecto de la aparición de la primera cadena con un centro de distribución nacional manteniendo constante la concentración. Ésta hace caer el precio relativo de los alimentos en $10,8 \%$. Y si a la primera cadena se le agrega la segunda, el precio relativo de los alimentos cae $20,9 \%$ en total. Vale decir, es claro que la presencia de una o dos cadenas desplaza la curva $p p$ hacia abajo — para cada nivel de concentración el precio relativo de los alimentos cae-.

Segundo ejercicio: la relación concentración-precio. Vimos líneas arriba que la aparición de la segunda cadena atenúa la relación 
concentración-precio. ¿Cuál es la magnitud económica? Si en una ciudad no hay una cadena con centro de distribución nacional, y el número equivalente de firmas cae en uno, el precio relativo de los alimentos aumenta en 2,8\% —ésta es la tradicional relación concentración-precio- - Sin embargo, una vez que aparece la primera cadena con un centro de distribución nacional, la relación entre concentración y precio es más débil: si el número equivalente de firmas cae en uno, el precio relativo de los alimento aumenta $1,4 \%$. La presencia de la segunda cadena con centro de distribución nacional atenúa esta relación aun más: si el número equivalente de firmas cae en uno, el precio relativo de los alimento aumenta sólo $0,4 \%$. Así, estos resultados muestran el sesgo de variables omitidas, el que lleva a sobrestimar la pendiente de la curva $p p$.

Tercer ejercicio: precios antes y después de la entrada de una cadena. Por último, supóngase que en el largo plazo y tras la aparición de dos cadenas con centro de distribución nacional salen dos firmas equivalentes (un ajuste parecido al que se describe en el Gráfico $\mathrm{N}^{\circ} 4$ ). Por cierto, tal cosa no ha ocurrido aún, como indica la evolución del número equivalente de firmas ciudad por ciudad. Pero en cualquier caso no parece haber razones para temer que la salida de competidores haga aumentar mucho el precio relativo de los alimentos. De hecho, aun si salen dos firmas equivalentes, la presencia de dos cadenas con centro de distribución nacional haría caer el precio relativo de los alimento en $20,1 \%$ en total —magnitud similar a la de la caída del precio relativo de los alimentos a nivel nacional—.

En conclusión. Con la aparición de la primera cadena con un centro de distribución nacional el precio relativo de los alimentos cae. La aparición de la segunda cadena hace caer el precio relativo aun más y, además, atenúa la relación concentración-precio. La caída del precio relativo no se le puede atribuir a la disminución de la concentración por entrada de nuevas firmas - de hecho a nivel local la concentración no varió mucho entre 1998 y 2006- Y Y aun si después del ajuste la concentración aumentase por salida de cadenas, el precio relativo de los alimentos sería permanentemente más bajo en la medida en que D\&S y Cencosud continúen compitiendo. 


\subsubsection{Robustez}

Métodos de estimación. El Cuadro $\mathrm{N}^{\circ} 10$ presenta varios chequeos adicionales de robustez. La columna 1 estima la ecuación (4.1) con mínimos cuadrados agrupados (pooled MCO), método que ignora la estructura del panel. La aparición de la primera cadena con centro de

CUADRO N ${ }^{\circ}$ 10: $\quad$ REGRESIONES TRIMESTRALES, CON SANTIAGO Y ESTIMADAS CON TRES MÉTODOS ALTERNATIVOS

\begin{tabular}{|c|c|c|c|c|c|}
\hline \multirow[t]{2}{*}{ Variable } & \multirow{2}{*}{$\begin{array}{l}\text { Pooled } \\
\text { MCO } \\
\text { (1) }\end{array}$} & \multicolumn{2}{|c|}{ Efectos fijos } & \multicolumn{2}{|c|}{ Efectos aleatorios } \\
\hline & & (2) & (3) & (4) & (5) \\
\hline NEF & $\begin{array}{l}-0,90 \\
(0,33) \\
{[0,007]}\end{array}$ & $\begin{array}{l}-3,96 \\
(0,80) \\
{[0,000]}\end{array}$ & $\begin{array}{l}-3,24 \\
(0,74) \\
{[0,000]}\end{array}$ & $\begin{array}{l}-2,42 \\
(0,62) \\
{[0,000]}\end{array}$ & $\begin{array}{l}-1,88 \\
(0,56) \\
{[0,001]}\end{array}$ \\
\hline $\mathrm{D}^{1}$ & $\begin{array}{l}-5,09 \\
(1,83) \\
{[0,005]}\end{array}$ & $\begin{array}{c}-12,79 \\
(3,00) \\
{[0,000]}\end{array}$ & $\begin{array}{c}-12,41 \\
(2,72) \\
{[0,000]}\end{array}$ & $\begin{array}{l}-8,04 \\
(2,59) \\
{[0,001]}\end{array}$ & $\begin{array}{l}-7,88 \\
(2,28) \\
{[0,001]}\end{array}$ \\
\hline $\mathrm{D}^{2}$ & $\begin{array}{l}-2,16 \\
(1,81) \\
{[0,234]}\end{array}$ & $\begin{array}{c}-12,28 \\
(1,74) \\
{[0,000]}\end{array}$ & $\begin{array}{c}-10,48 \\
(1,68) \\
{[0,000]}\end{array}$ & $\begin{array}{c}-10,60 \\
(1,71) \\
{[0,000]}\end{array}$ & $\begin{array}{l}-8,48 \\
(1,65) \\
{[0,000]}\end{array}$ \\
\hline $\mathrm{D}^{1} \times \mathrm{NEF}$ & $\begin{array}{l}-0,12 \\
(0,45) \\
{[0,798]}\end{array}$ & $\begin{array}{l}1,70 \\
(0,64) \\
{[0,008]}\end{array}$ & $\begin{array}{l}1,59 \\
(0,58) \\
{[0,006]}\end{array}$ & $\begin{array}{l}0,75 \\
(0,57) \\
{[0,190]}\end{array}$ & $\begin{array}{l}0,69 \\
(0,51) \\
{[0,173]}\end{array}$ \\
\hline $\mathrm{D}^{2} \times \mathrm{NEF}$ & $\begin{array}{l}-0,31 \\
(0,42) \\
{[0,460]}\end{array}$ & $\begin{array}{l}1,38 \\
(0,43) \\
{[0,001]}\end{array}$ & $\begin{array}{c}1,21 \\
(00,38) \\
{[0,002]}\end{array}$ & $\begin{array}{l}1,00 \\
(0,42) \\
{[0,016]}\end{array}$ & $\begin{array}{l}0,84 \\
(0,37) \\
{[0,003]}\end{array}$ \\
\hline $\begin{array}{l}\text { Efecto ciudad } \\
\text { Efecto fijo período }\end{array}$ & $\begin{array}{l}\text { No } \\
\text { No }\end{array}$ & $\begin{array}{l}\text { Sí } \\
\text { No }\end{array}$ & $\begin{array}{l}\text { Sí } \\
\text { Sí }\end{array}$ & $\begin{array}{l}\text { Sí } \\
\text { No }\end{array}$ & $\begin{array}{l}\text { Sí } \\
\text { Sí }\end{array}$ \\
\hline$n$ & 663 & 663 & 663 & 663 & 663 \\
\hline $\mathrm{R}^{2}$ within & - & 0,30 & 0,48 & 0,29 & 0,47 \\
\hline $\mathrm{R}^{2}$ between & - & 0,16 & 0,16 & 0,15 & 0,15 \\
\hline $\mathrm{R}^{2}$ overall & 0,25 & 0,22 & 0,32 & 0,23 & 0,34 \\
\hline
\end{tabular}

Test de Breush-Pagan

$\chi^{2}$

Estadístico $p$ 
distribución nacional sigue haciendo caer el precio de los alimentos, aunque los coeficientes de las variables de interacción ya no son estadísticamente distintos de cero. Pero, en todo caso, un test de Breush-Pagan resulta significativo, indicando que la regresión de mínimos cuadrados agrupados es inapropiada — se trata, efectivamente, de un panel—.

Las regresiones presentadas en el Cuadro $\mathrm{N}^{\circ} 7$ corresponden a estimadores de efectos fijos. Aunque un test de Hausman rechaza la hipótesis nula de efectos aleatorios, presentamos una estimación de la ecuación (4.1) con efectos aleatorios a pesar de todo. Se aprecia en el Cuadro $\mathrm{N}^{\circ} 10$, columnas 4 y 5 , que los resultados son parecidos, aunque $\hat{\delta}_{1}$ ya no es estadísticamente significativo a los niveles de confianza estándar (para facilitar la comparación, en la columna 3 del Cuadro $\mathrm{N}^{\mathrm{0}} 10$ hemos reproducido la estimación trimestral con efectos fijos) ${ }^{33}$.

En realidad, tal como se puede apreciar comparando las columnas 2, 3, 4 y 5, la estimación es robusta, independientemente de si se estima con efectos fijos o aleatorios, o si se incluye o excluye el efecto fijo temporal. En todos los casos los coeficientes son de magnitud similar y, salvo $\hat{\delta}_{1}$ cuando se estima con efectos aleatorios, todos son estadísticamente significativos a los niveles estándares de confianza.

\section{ALGUNAS IMPLICANCIAS}

\subsection{Fusiones y el sesgo por omisión de variables}

La relación concentración-precio empírica se suele ocupar para evaluar el efecto de una fusión sobre el precio. Por ejemplo, en la sección 8 de su trabajo, Gómez-Lobo y González (2007) simulan el efecto de algunas fusiones, que presentamos en el Cuadro $\mathrm{N}^{\circ} 11$. Así, concluyen que si D\&S adquiere El Pilar en Talca, el precio relativo de los alimentos debería aumentar 8,1\%. Y si Cencosud adquiere Korlaet e Infante en Antofagasta, el precio relativo de los alimentos debería aumentar $7,9 \%$.

${ }^{33}$ Nótese que el test de Breusch-Pagan indica que la estimación por datos agrupados es inapropiada. 
CUADRO N 11: REEXAMINANDO EL EFECTO DE UNA FUSIÓN

\begin{tabular}{|c|c|c|c|c|c|c|}
\hline & $\begin{array}{c}\text { (1) } \\
\text { Número } \\
\text { equivalente } \\
\text { de firmas } \\
\text { (inicial) }\end{array}$ & $\begin{array}{c}\text { (2) } \\
\text { Número } \\
\text { equivalente } \\
\text { de firmas } \\
\text { (final) }\end{array}$ & $\begin{array}{l}\text { (3) } \\
\text { Cambio del } \\
\text { número } \\
\text { equivalente } \\
\text { de firmas }\end{array}$ & $\begin{array}{c}\text { (4) } \\
\text { Aumento } \\
\text { del precio, } \\
\text { nuestra } \\
\text { estimación }\end{array}$ & $\begin{array}{c}\text { (5) } \\
\text { Aumento } \\
\text { del precio, } \\
\text { Gómez-Lobo } \\
\text { y González } \\
\text { (2007) }\end{array}$ & $\begin{array}{c}(6) \\
\text { Aparición } \\
\text { de la } \\
\text { segunda } \\
\text { cadena }\end{array}$ \\
\hline Antofagasta $^{1}$ & 3,67 & 1,42 & $-2,25$ & $0,9 \%$ & $7,9 \%$ & 2000 \\
\hline Antofagasta ${ }^{2}$ & 3,67 & 1,97 & $-1,69$ & $0,7 \%$ & $4,3 \%$ & 2000 \\
\hline Copiapó $^{3}$ & 2,40 & 1,55 & $-0,84$ & $0,3 \%$ & $2,7 \%$ & 2006 \\
\hline La Serena ${ }^{3}$ & 3,00 & 1,60 & $-1,40$ & $0,5 \%$ & $4,4 \%$ & 2000 \\
\hline Santiago $^{4}$ & 4,36 & 4,03 & $-0,33$ & $0,1 \%$ & $0,4 \%$ & 2001 \\
\hline Talca $^{5}$ & 4,83 & 1,85 & $-2,98$ & $1,1 \%$ & $8,1 \%$ & 2000 \\
\hline Linares $^{5}$ & 2,48 & 1,49 & $-0,99$ & $0,4 \%$ & $3,3 \%$ & 2006 \\
\hline
\end{tabular}

Notas:

${ }^{1}$ Cencosud adquiere Korlaet e Infante. ${ }^{2}$ D\&S adquiere Korlaet. ${ }^{3}$ D\&S adquiere Deca y Rendic. ${ }^{4}$ Cencosud adquiere Economax. ${ }^{5} \mathrm{D} \& \mathrm{~S}$ adquiere El Pilar.

Fuentes: Columnas 1 a 3 y 5 construidas con la información contenida en Tabla $\mathrm{N}^{\circ}$, Gómez-Lobo y González (2007). Columna 4: cálculos propios: $-0,44 \times \frac{\Delta \mathrm{NEF}}{115,06} 0$, Columna 6: Cuadro 40.

Sin embargo, al ignorar el sesgo por omisión de variables que tiende a exagerar la pendiente de la curva $p p$, se exagera el efecto de una fusión. La columna 4 del Cuadro $\mathrm{N}^{\circ} 11$ muestra que una vez corregido este sesgo, el aumento de precios tras una fusión es un orden de magnitud menor. Por ejemplo, en Talca el precio relativo de los alimentos debería aumentar sólo 1,1\% en vez de 8,1\% y en Antofagasta, $0,9 \%$ en vez de $7,9 \%$.

\section{2. ¿Por qué no aumentó la concentración local?}

Vimos que, al menos entre 1998 y 2006, no parece que la concentración a nivel local haya variado mucho. Grosso modo, parecería que la expansión de D\&S y Cencosud ha reemplazado a firmas 
locales pero que no ha cambiado mucho el número de cadenas de supermercados en cada ciudad. Por supuesto, nuestro modelo teórico es incapaz de explicar este hecho, porque supone que todas las firmas son iguales. Por lo tanto, una vez que cambia la tecnología, en el largo plazo sólo debieran quedar cadenas con centro de distribución nacional.

Por supuesto, el defecto está en el modelo y no en la realidad. Es bien sabido a esta altura que las diferencias de productividad entre firmas de un mismo sector con acceso a tecnologías similares son muy grandes $^{34}$. Por lo tanto, es perfectamente posible que una cadena local comparativamente eficiente sobreviva a la presencia de dos cadenas con centro de distribución nacional, aunque obteniendo utilidades más bajas que antes.

Hay en todo caso una explicación complementaria, a saber: que una buena parte del crecimiento de las cadenas de supermercados es a costa de reemplazo de almacenes y no sólo de otros supermercados. Si así fuera, esto indicaría que aquéllos compiten con los supermercados. De hecho, Galetovic y Sanhueza (2006) argumentan que los almacenes son tomadores de precio ${ }^{35}$. Una implicancia es que la participación de lo almacenes cae cuando los precios bajan.

\subsection{Testeando el posible ejercicio de poder de compra}

Como ya vimos, el requerimiento de la Fiscalía Nacional Económica acusó a D\&S y Cencosud de ejercer poder de compra. Nuestros resultados también se pueden usar para examinar esta tesis.

La tesis de la Fiscalía es que el aumento de la concentración de las ventas les ha permitido a las dos cadenas más grandes ejercer poder de compra. Tal como lo muestran Galetovic y Sanhueza (2006), esta tesis tiene una implicancia observable, a saber: que, todo lo demás constante, el ejercicio de poder de compra implica mayores precios

\footnotetext{
${ }^{34}$ La regularidad es que la eficiencia media en una industria sea alrededor del 65\% de la eficiencia de la firma más eficiente. Por ejemplo, para formarse una idea, Caves (1992) detecta que la eficiencia industrial promedio en cuatro países desarrollados (Japón, Estados Unidos, Australia y el Reino Unido) está entre 65 y $70 \%$ de la firma más eficiente. Y Tybout (2000), quien reseña la evidencia para países en desarrollo, indica que, sorprendentemente, las diferencias de productividad entre empresas en países en desarrollo no son muy distintas de las que se observan en países desarrollados.

${ }^{35}$ El término técnico es competitive fringe y se le debe a Stigler (1965).
} 
aguas abajo, porque un oligopsonista reduciría la cantidad transada. Más aun, porque el ejercicio de poder de compra en un momento dado sólo depende del número de compradores activos en ese momento, la concentración se puede tratar como variable exógena ${ }^{36-37}$.

Por eso, si el efecto es importante en la práctica, como parecía creer la Fiscalía, el ejercicio de poder de compra debiera haberse intensificado y reflejado rápidamente en los precios entre 1997 y 2000 y, sobre todo, entre 2002 y 2004, cuando las ventas de supermercados se concentraron fuertemente. Por supuesto, y tal como se aprecia en el Gráfico $N^{0} 1$, tal aumento de precios aguas abajo no ocurrió. Más importante aun, si las cadenas ejercieran poder de compra, la entrada en una ciudad de una cadena debiera reflejarse en aumentos de precio, no en caídas sustantivas, tal como ocurre en la práctica. Así, nuestros resultados indican que es muy improbable que D\&S o Cencosud, individualmente o en conjunto, hayan ejercido poder de compra entre 1998 y 2006.

\subsection{Evaluando lo que ocurrió entre 1998 y 2006}

Por todo lo anterior, nos parece apropiado concluir que tanto a nivel nacional como a nivel local la evidencia es categórica: la expansión de las cadenas con centro de distribución nacional entre 1998 y 2006 hizo caer el precio relativo de los alimentos, intensificó la competencia en precios y atenuó la relación concentración-precio. Por lo argumentado en este trabajo y en Galetovic y Sanhueza (2006), la caída del precio relativo no tiene que ver con el ejercicio de poder de compra aguas arriba, sino con los cambios tecnológicos asociados con la irrupción de los centros de distribución y el manejo centralizado de inventarios.

Por eso, a menos que ambas cadenas consigan coludirse en el futuro y además bloquear la entrada (cuestión sobre la cual no hay ni indicios ni evidencia de que esté ocurriendo o vaya a ocurrir), y mientras en una ciudad coexistan D\&S y Cencosud y compitan como lo nunca ocurre.

${ }^{36}$ Salvo, por cierto, que se suponga que el mercado es desafiable, lo que casi

${ }^{37}$ Evidentemente, la concentración es endógena en el largo plazo. Pero en el corto plazo la concentración es exógena desde el punto de vista del ejercicio del poder de compra, porque la intensidad del poder de compra depende sólo del número de firmas activas, el que es fijo y exógeno en el corto plazo. 
han hecho hasta la fecha, la caída del precio relativo es permanente y no se revertirá, incluso si en cada ciudad salen una o dos cadenas locales y el número equivalente de firmas disminuye en esa magnitud.

\section{EPÍLOGO: LA SENTENCIA DEL HONORABLE TRIBUNAL DE DEFENSA DE LA LIBRE COMPETENCIA}

El 8 de mayo del 2008 el Honorable Tribunal de Defensa de la Libre Competencia (TDLC) falló el requerimiento de la Fiscalía obligando a Cencosud a consultar toda compra de nuevas cadenas. La fundamentación del TDLC sugiere que, en su opinión, la concentración de la industria no ha sido conveniente, y por eso vale la pena contrastar su fundamentación con los resultados de este trabajo ${ }^{38}$.

El TDLC opina que las cadenas están materializando diversas economías de escala, ámbito y densidad, en buena parte debido al aumento de la escala eficiente causado por los centros de distribución. También apunta que atienden a un número creciente de consumidores porque han expandido sus operaciones en distintos formatos y tamaños de tiendas de supermercados. Sin embargo, en su opinión estas mayores eficiencias y el ajuste de los formatos a las preferencias de los consumidores serían fuente de barreras a la entrada. Además, las dos cadenas pueden ejercer poder de compra y habrían tomado terrenos estratégicamente. Por eso concluye que:

[...] una política de crecimiento [...] basada en la compra de competidores incrementa no sólo la concentración de la industria [...], sino también las dificultades que tienen los rivales con menores escalas de operación y nuevos entrantes para disciplinar con efectividad y en plazos razonables a dicha empresa, pudiendo favorecer el ejercicio de poder de mercado $[\ldots]^{39}$.

En otras palabras, y aunque la sentencia se refiere únicamente a Cencosud, las dos cadenas tendrían una ventaja irremontable que haría muy difícil la entrada de otra de tamaño similar y casi imposible la entrada o sobrevivencia de cadenas más pequeñas. Así las cosas, la única variable que le queda al TDLC para mitigar los efectos dañinos de

\footnotetext{
${ }^{38}$ En la discusión que sigue agradecemos los útiles comentarios de Rafael Gaete.

${ }^{39}$ Numeral centésimo de la Sentencia.
} 
la concentración es impedir el crecimiento a través de adquisiciones. Por eso, no es sorprendente y tiene lógica que el TDLC haya obligado a Cencosud a consultar cualquier adquisición futura. Seguramente, examinando cada adquisición, el TDLC espera limitar las economías que pueda alcanzar una cadena y la variedad de formatos que se puede explotar, reduciendo así su ventaja.

No se puede negar que la decisión del TDLC es casi una implicancia lógica de sus premisas. ¿Pero son correctas sus premisas? Es indudable que las economías de escala, ámbito o densidad pueden ser fuente de monopolio natural, pero no es éste el caso, pues seguramente nadie estima que el equilibrio de la industria sea con una sola cadena de supermercados. Por eso, sostener que estas economías creen barreras a la entrada es a lo menos discutible y en todo caso cuestión empírica. Y el hecho es que la evidencia rechaza la principal implicancia observable de la tesis del TDLC. En efecto, si lo fueran, cada vez que una cadena con centro de distribución entra en una ciudad debiera incrementar las barreras a la entrada y los precios debieran aumentar, no caer. De manera similar, a lo largo del tiempo, el aumento de la concentración debiera haber sido acompañado por aumentos de precio, pero vimos que ocurrió todo lo contrario. En ese sentido, es un tanto sorprendente que la sentencia no mencione la caída del precio relativo de los alimentos entre 1998 y 2006.

Así las cosas, en nuestra opinión la sentencia le impuso una carga innecesaria a Cencosud —la obligación de consultar — porque la evidencia disponible ya en 2007 sugiere que el peligro potencial que se pretendía mitigar era a lo menos improbable y seguramente inexistente. De hecho, esto quedó de manifiesto durante el último año. En efecto, en el intertanto han surgido dos cadenas más, Supermercados del Sur y SMU, y una de ellas ya anunció que construirá su centro de distribución. Estas cadenas han continuado consolidando a la industria y han invertido en nuevas tiendas. En realidad, esto no es sino la continuación de la misma película: la consolidación ocurre porque hay maneras más eficientes de distribuir alimentos; a medida que las ganancias de eficiencia se materializan, los precios caen; las firmas incapaces de adoptar la tecnología eficiente salen o son adquiridas por otras más eficientes. Se trata de una historia de entrada, concentración y competencia. 


\section{APÉNDICE}

\section{A. Cuadros complementarios}

CUADRO N ${ }^{\circ}$ A1: TEST DE KRUSKAL-WALLIS PARA EL NÚMERO EQUIVALENTE DE FIRMAS

\begin{tabular}{lccc}
\hline Observaciones & $\begin{array}{c}\text { Rank } \\
\text { sum }\end{array}$ & $\begin{array}{c}\text { Rank } \\
\text { mean }\end{array}$ \\
\hline 1998 & 16 & $1.409,0$ & 88,1 \\
1999 & 16 & $1.491,0$ & 93,2 \\
2000 & 16 & $1.536,0$ & 96,0 \\
2001 & 16 & $1.590,5$ & 99,4 \\
2002 & 24 & $2.309,0$ & 96,2 \\
2003 & 24 & $2.280,0$ & 95,0 \\
2004 & 24 & $2.101,5$ & 87,6 \\
2005 & 24 & $2.134,0$ & 88,9 \\
2006 & 24 & $2.169,0$ & 90,4 \\
& & & \\
$\chi^{2}$ & 0,974 & & \\
Estadístico $p$ & 0,99841 & & \\
\hline
\end{tabular}

CUADRO N ${ }^{\circ}$ A2: TEST DE KRUSKAL-WALLIS PARA EL PRECIO RELATIVO DE LOS ALIMENTOS

\begin{tabular}{lccc}
\hline & Observaciones & $\begin{array}{c}\text { Rank } \\
\text { sum }\end{array}$ & $\begin{array}{c}\text { Rank } \\
\text { mean }\end{array}$ \\
\hline & 16 & $2.662,0$ & 166,4 \\
1998 & 16 & $1.785,0$ & 111,6 \\
2000 & 16 & $1.807,0$ & 112,9 \\
2001 & 16 & $1.131,0$ & 70,7 \\
2002 & 24 & $1.455,0$ & 60,6 \\
2003 & 24 & $1.705,0$ & 71,0 \\
2004 & 24 & $1.615,0$ & 67,3 \\
2005 & 24 & $2.019,0$ & 84,1 \\
2006 & 24 & $2.841,0$ & 118,4 \\
& & & \\
$\chi^{2}$ & 61,998 & & \\
Estadístico $p$ & 0,0001 & & \\
\hline
\end{tabular}


CUADRO No A3: REGRESIONES MENSUALES COMPARADAS

(Efectos fijos y efectos aleatorios)

\begin{tabular}{|c|c|c|c|c|}
\hline \multirow[t]{2}{*}{ Variable } & \multicolumn{2}{|c|}{ Con Santiago } & \multicolumn{2}{|c|}{ Sin Santiago } \\
\hline & $\begin{array}{c}\text { (1) } \\
\text { Efectos fijos }\end{array}$ & $\begin{array}{c}\text { (2) } \\
\text { Efectos aleatorios }\end{array}$ & $\begin{array}{c}\text { (3) } \\
\text { Efectos fijos }\end{array}$ & $\begin{array}{c}(4) \\
\text { Efectos aleatorios }\end{array}$ \\
\hline NEF & $\begin{array}{l}-3,15 \\
(0,29) \\
{[0,000]}\end{array}$ & $\begin{array}{l}-2,75 \\
(0,34) \\
{[0,000]}\end{array}$ & $\begin{array}{l}-2,67 \\
(0,38) \\
{[0,000]}\end{array}$ & $\begin{array}{l}-2,39 \\
(0,34) \\
{[0,000]}\end{array}$ \\
\hline $\mathrm{D}^{1}$ & $\begin{array}{c}-10,44 \\
(1,39) \\
{[0,087]}\end{array}$ & $\begin{array}{l}-9,04 \\
(1,30) \\
{[0,087]}\end{array}$ & $\begin{array}{l}-9,98 \\
(1,39) \\
{[0,000]}\end{array}$ & $\begin{array}{l}-8,85 \\
(1,31) \\
{[0,000]}\end{array}$ \\
\hline $\mathrm{D}^{2}$ & $\begin{array}{c}-10,00 \\
(0,86) \\
{[0,000]}\end{array}$ & $\begin{array}{l}-9,26 \\
(0,85) \\
{[0,000]}\end{array}$ & $\begin{array}{l}-8,48 \\
(0,90) \\
{[0,000]}\end{array}$ & $\begin{array}{l}-7,78 \\
(0,88) \\
{[0,000]}\end{array}$ \\
\hline $\mathrm{D}^{1} \times \mathrm{NEF}$ & $\begin{array}{l}1,47 \\
(0,29) \\
{[0,000]}\end{array}$ & $\begin{array}{l}1,22 \\
(0,28) \\
{[0,000]}\end{array}$ & $\begin{array}{l}1,44 \\
(0,29) \\
{[0,000]}\end{array}$ & $\begin{array}{l}1,24 \\
(0,28) \\
{[0,000]}\end{array}$ \\
\hline $\mathrm{D}^{2} \times \mathrm{NEF}$ & $\begin{array}{c}1,40 \\
(00,20) \\
{[0,000]}\end{array}$ & $\begin{array}{c}1,29 \\
(00,19) \\
{[0,000]}\end{array}$ & $\begin{array}{c}0,93 \\
(00,21) \\
{[0,000]}\end{array}$ & $\begin{array}{c}0,82 \\
(00,21) \\
{[0,000]}\end{array}$ \\
\hline$n$ & 1.986 & 1.986 & 1.887 & 1.887 \\
\hline $\begin{array}{l}R^{2} \text { within } \\
R^{2} \text { between } \\
R^{2} \text { overall }\end{array}$ & $\begin{array}{l}0,60 \\
0,20 \\
0,44\end{array}$ & $\begin{array}{l}0,60 \\
0,22 \\
0,45\end{array}$ & $\begin{array}{l}0,62 \\
0,22 \\
0,47\end{array}$ & $\begin{array}{l}0,62 \\
0,24 \\
0,48\end{array}$ \\
\hline Test de Hausn & & & & \\
\hline $\begin{array}{l}\chi^{2} \\
\text { Estadístico } p\end{array}$ & $\begin{array}{c}26,53 \\
{[10,00]}\end{array}$ & & $\begin{array}{c}26,81 \\
{[10,00]}\end{array}$ & \\
\hline
\end{tabular}

Notas: (Desviación estándar en paréntesis.)

[Estadístico $p$ en corchetes.] 


\section{B. Algunos comentarios sobre Gómez-Lobo y González (2007)}

En este apéndice comentamos el trabajo de Gómez-Lobo y González (2007), el que también estima una relación concentración-precio con los mismos datos, pero llega a conclusiones un tanto distintas.

La principal ecuación que estiman Gómez-Lobo y González (2007) es la siguiente:

$\ln p_{i, t}=\alpha+\lambda \times \ln p_{i, t-1}+\beta \times \ln \mathcal{H}_{i, t-1}+\Theta^{\prime} \mathrm{x}_{i, t}+\zeta_{i}+\eta_{i}+\varepsilon_{i, t}$

donde $\mathrm{x}_{i, t}$ es un vector de variables de control, $\zeta_{i}$ es un efecto fijo por ciudad invariante durante el período muestral y $\eta_{t}$ es un efecto fijo por mes. Obtienen que el coeficiente $\beta$ es significativo y de mayor magnitud que el nuestro. A continuación explicamos por qué.

\section{B.1. Omisión de variables}

En la regresión (B.1) se omiten variables, porque esta especificación no controla por la aparición de supermercados con un centro de distribución nacional en una determinada ciudad. Por cierto, GómezLobo y González (2007, p. 15) afirman que los resultados obtenidos a partir de esta especificación, y en particular la relación positiva y significativa entre precios y concentración,

[...] no se debe[n] a diferencias de costos entre regiones, ya que, [...] estas diferencias están siendo controladas por el efecto individual de cada ciudad.

Esto es incorrecto. Los efectos fijos controlan por factores no observables que no varían en el tiempo, para cada ciudad. La aparición de una cadena con un centro de distribución nacional en una ciudad determinada cambia la estructura de costos relevantes para la competencia en esa ciudad a partir de esa fecha y no puede ser capturada por un efecto invariante.

\section{B.2. El ajuste parcial es inapropiado}

Nótese que el lado derecho de la ecuación (B.1) incluye el precio de los alimentos rezagado en un mes. Gómez-Lobo y González (2007) lo justifican argumentando que los supermercados ajustarían lentamen- 
te los precios de los productos que venden cuando cambia el precio de compra. Una parte de su argumento es (en sus propias palabras) teórico. El sustento empírico, afirman, es el siguiente:

Por otro lado, los estudios empíricos de Levy, Bergen, Dutta y Venable (1997) y Slade (1998) sobre la industria de los supermercados en Estados Unidos, indican que los costos de cambiar precios son significativos en esta industria y generan dinámicas de precios como las postuladas por el modelo de ajuste parcial planteado aquí. Slade (1998), además, introduce la idea de que los supermercados no cambian inmediatamente sus precios, o no lo hacen en la magnitud completa que les permiten las condiciones del mercado, para no afectar su reputación (goodwill) entre sus clientes.

Pero tal justificación es inapropiada. De un lado, Slade (1998) examina solamente los ajustes del precio de las galletas saladas (saltine crackers) en diez almacenes (grocery stores) de Williamsport, Pennsylvania, durante 1984-1985, un pueblo pequeño sin pueblos vecinos en un radio de a lo menos cien millas al momento del estudio. No es, claramente, un estudio del ajuste de precios en supermercados.

Del otro lado, Levy et al. (1997) examinan precios semanales y encuentran que en las cadenas de supermercados consideradas en su estudio los costos de alrededor de 800 a 1.000 productos varían cada semana. Cuando cambian los costos, entre el 70 y $80 \%$ de los precios se ajusta en una semana; es decir, es muy improbable que el ajuste de precios tome más de un mes. Por eso, si bien encuentran que los así llamados menu costs (el costo de cambiar los precios) son importantes, su trabajo no justifica el supuesto de Gómez-Lobo y González (2007) - a pesar de los menu costs, los ajustes de precios toman mucho menos que un mes- ${ }^{40}$.

Por último, el comportamiento de Cencosud también sugiere que el ajuste de precios es frecuente y rápido. El Cuadro $\mathrm{N}^{\circ} \mathrm{B} 1$ muestra el número de veces en que se cambió el precio en cada uno de 22 locales Jumbo en mayo de 2007. Los cambios de precio son frecuentes. De hecho, el precio de los alimentos perecibles, que pesan alrededor de $50 \%$ en la canasta de alimentos que usaron Lira et al. (2007) y GómezLobo y González (2007), cambia varias veces dentro de cada mes.

${ }^{40}$ Es interesante notar que Levy et al. (1997) afirman que los cambios de precios semanales son frecuentes porque a nivel local la industria de los supermercados es extremadamente competitiva (“At the local level this industry is extremely competitive”). 


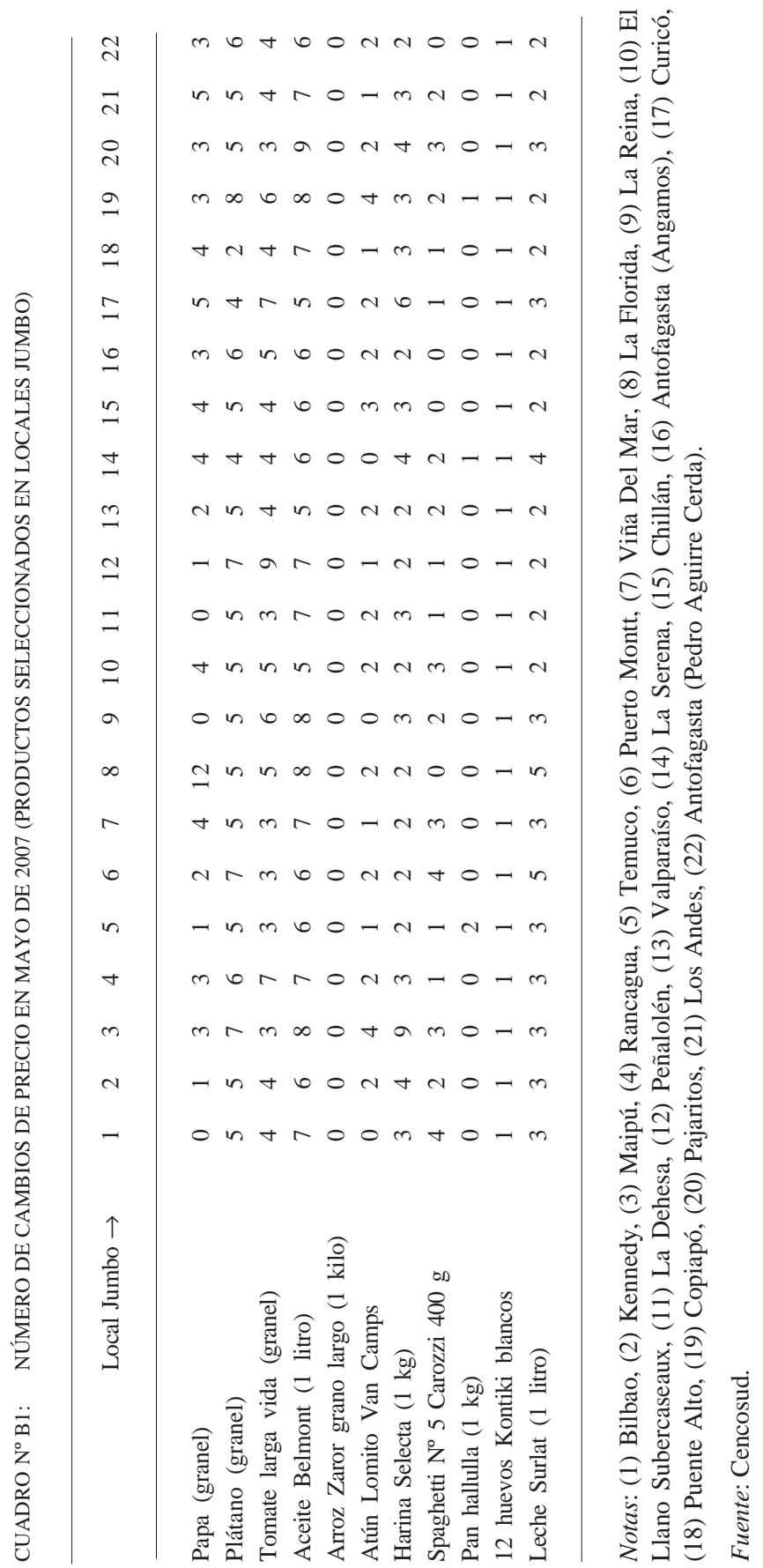




\section{B.3. Ajuste parcial, seudopersistencia y sus consecuencias econométricas}

Es importante notar que se justifica excluir el ajuste parcial de precios aun si éstos mostraran persistencia estadística. ¿Por qué?

Notemos que es perfectamente posible que el precio de un bien en $t$ sea similar al precio del bien en $t+1$, pero que ambos precios sean independientes temporalmente. Para que ello ocurra basta con que las preferencias de las personas y la estructura de costos no cambien entre $t$ y $t+1$-la oferta y la demanda son similares en ambos períodos-. En ese caso, el precio de equilibrio en $t$ será similar al precio de equilibrio en $t+1$, pero no habrá vínculo intertemporal entre ambos, a pesar de que en los datos aparecerá una seudopersistencia. Esta seudopersistencia aparece porque la frecuencia con que se mide la variable es menor que la frecuencia con que ocurren cambios en sus determinantes fundamentales ${ }^{41}$.

Ahora bien, a pesar de que el precio relativo de los alimentos se determine independientemente mes a mes, la estabilidad de las preferencias de los consumidores y de las estructuras de costos de las empresas causa correlación serial estadística -el precio en $t+1$ es similar al precio en $t$ - Esta dependencia estadística puede inducir un error de especificación cuando se modela la relación concentración-precio y se incluye la variable dependiente rezagada al lado derecho. Esto, precisamente, le ocurre a la estimación de Gómez-Lobo y González (2007). Las consecuencias econométricas son graves. No sólo se pierde eficiencia, como en el caso clásico de variables intrusas; peor aun, se sesgan hacia abajo los coeficientes de las variables que efectivamente pertenecen al modelo. Así ocurre porque, dada la similitud del precio en $t$ con el precio en $t-1$, en la regresión (B.1) la variabilidad del corte transversal del precio relativo de los alimentos en $t-1$ "explica" gran parte de la variabilidad del precio en $t$, sesgando a la baja a los coeficientes estimados del resto de las variables del modelo. Este efecto aparece claramente cuando se estima con y sin el precio relativo de los

${ }^{41}$ Por ejemplo, supóngase que los fundamentales de una acción no cambian durante varios días. El precio de la acción en el día $t$ es la esperanza del precio en el día $t+1$ y el precio en el día $t+1$ será similar al precio en el día $t$. Sin embargo, es claro que esto no se debe a que ambos precios estén vinculados intertemporalmente. Todo lo contrario, cualquier vínculo intertemporal sistemático sería arbitrado. 
alimentos rezagado la regresión (B.1) de Gómez-Lobo y González (resultados en el Cuadro $\mathrm{N}^{\circ} \mathrm{B} 2$ ) y nuestra regresión (4.1) (resultados en el Cuadro $\mathrm{N}^{\circ} \mathrm{B} 3$ ).

En efecto, tal como se puede ver en las columnas 3 y 4 del Cuadro $\mathrm{N}^{\circ} \mathrm{B} 2$, si la regresión (B.1) se estima sin el precio rezagado, el coeficiente de $\ln \mathcal{H}$ aumenta en valor absoluto en un orden de magnitud — vale decir, Gómez-Lobo y González (2007) hubieran encontrado un efecto de un orden de magnitud mayor de la concentración sobre el precio (aunque, por supuesto, sujeto al sesgo por omisión de variables)-.

De manera similar, las columnas 1 y 2 del Cuadro $\mathrm{N}^{\circ} \mathrm{B} 3$ muestran que cuando se incluye el precio relativo de los alimentos rezagado, la magnitud de los coeficientes del resto de las variables explicativas, y en particular el del número equivalente de firmas, se reducen apreciablemente (para comparar, hemos reproducido nuestra estimación trimestral de (4.1), la columna 6 del Cuadro $\mathrm{N}^{\circ}$ 6, en la columna 3 del Cuadro $\mathrm{N}^{\circ} \mathrm{B} 3$ ). Aun así, es interesante notar que el coeficiente de $D^{1}$, $\hat{\gamma}_{1}$, y el coeficiente de interacción con NEF, $\delta_{1}$, retienen los signos esperados y son significativamente diferentes de cero. Estos resultados confirman la robustez de la especificación propuesta (regresión 4.1) y son evidencia adicional de que la aparición de cadenas con un centro de distribución nacional en una ciudad induce caídas significativas del precio relativo de los alimentos.

Sea como fuere, cuando la variable dependiente exhibe persistencia estadística puede convenir tomarla en cuenta al estimar la relación concentración-precio. Por cierto, incluir el rezago del precio no es el camino apropiado, porque esta variable no es uno de los fundamentales del precio en $t$. Más apropiado es utilizar como variable dependiente la expectativa condicional del precio, variable que por construcción es ortogonal al residuo de la regresión entre $p_{i, t} \mathrm{y}$ su polinomio de rezagos. Para esto, consideramos el siguiente modelo autorregresivo de $p_{i, t^{*}}$ :

$$
p_{i, t}=c+\phi_{1} \times p_{i, t-1}+\phi_{2} \times p_{i, t-2}+\ldots+\phi_{l} \times p_{i, t-l}+v_{i, t}
$$

con $i=1, \ldots, 24$. 
CUADRO Nº B2: $\quad$ LAS REGRESIONES DE GÓMEZ-LOBO Y GONZÁLEZ (2007), CON Y SIN EL PRECIO RELATIVO DE LOS ALIMENTOS REZAGADO

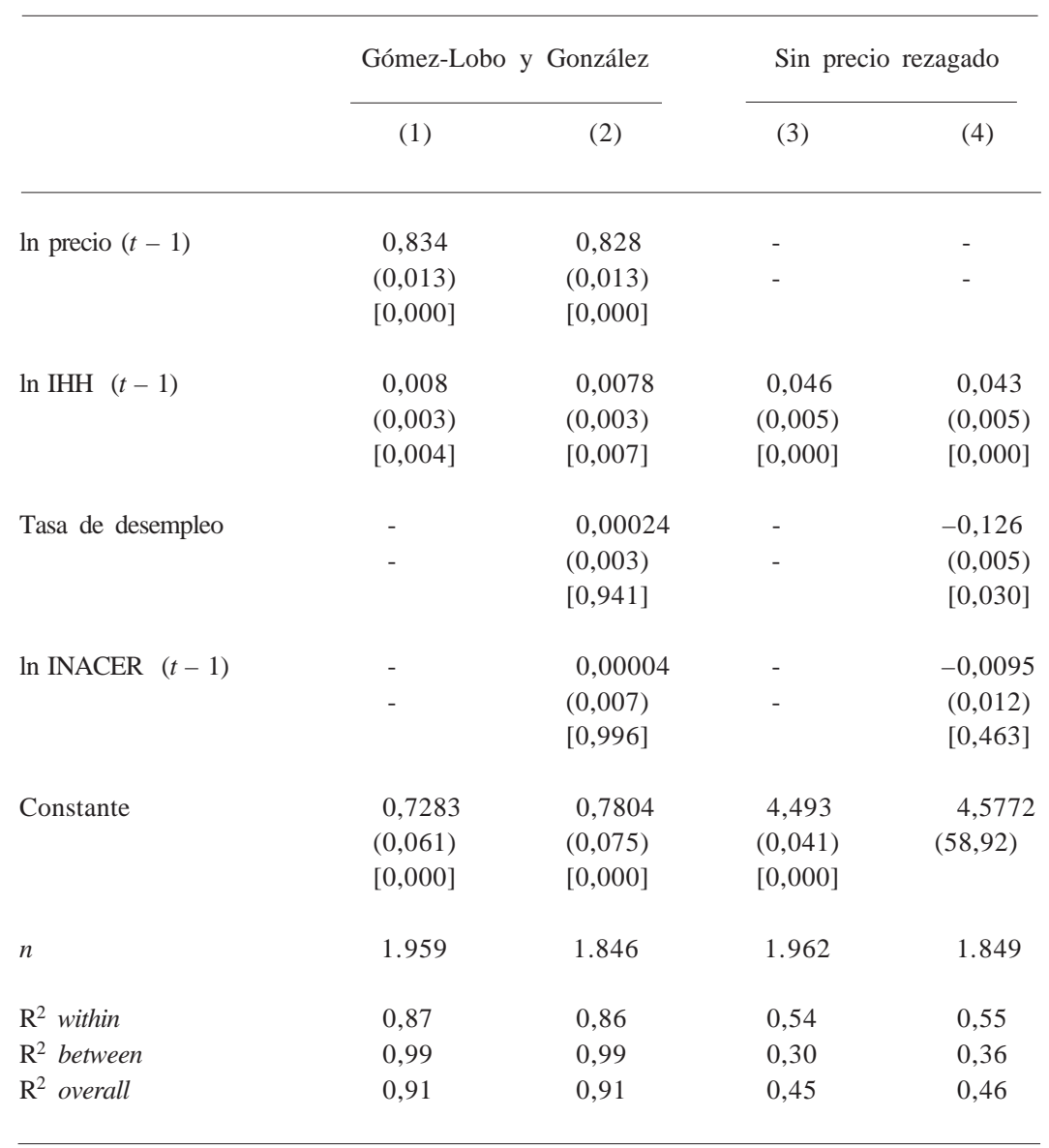

Notas: (Desviación estándar en paréntesis.)

[Estadístico $p$ en corchetes.]

En 15 ciudades un AR(1) representa adecuadamente el proceso del precio relativo de los alimentos. En cinco ciudades un AR(2) es apropiado, mientras que en las restantes cuatro ciudades los precios no muestran persistencia estadística. Así, para estimar la expectativa condicional de precios utilizamos

$$
\mathrm{E}_{t}\left(p_{i, t+1}\right)=c+\phi_{1} \times p_{i, t}+\phi_{2} \times p_{i, t-1},
$$


CUADRO N B3: REGRESIONES TRIMESTRALES CON INERCIA

\begin{tabular}{|c|c|c|c|c|}
\hline & \multicolumn{2}{|c|}{ Con precios rezagados } & \multicolumn{2}{|c|}{ Sin precios rezagados } \\
\hline & $\begin{array}{c}\text { (1) } \\
\text { Efectos fijos }\end{array}$ & $\begin{array}{l}\text { (2) } \\
\text { Arellano-Bond }\end{array}$ & $\begin{array}{c}\text { (3) } \\
\text { Efectos fijos } \\
\text { con precio } \\
\text { efectivo }\end{array}$ & $\begin{array}{c}\text { (4) } \\
\text { Efectos fijos } \\
\text { con precio } \\
\text { proyectado }\end{array}$ \\
\hline$p_{t-1}$ & $\begin{array}{l}0,78 \\
(0,02) \\
{[0,000]}\end{array}$ & $\begin{array}{l}0,77 \\
(0,03) \\
{[0,000]}\end{array}$ & - & - \\
\hline NEF & $\begin{array}{l}-0,86 \\
(0,44) \\
{[0,051]}\end{array}$ & $\begin{array}{l}-1,33 \\
(0,56) \\
{[0,016]}\end{array}$ & $\begin{array}{l}-3,24 \\
(0,74) \\
{[0,000]}\end{array}$ & $\begin{array}{l}-1,96 \\
(0,71) \\
{[0,006]}\end{array}$ \\
\hline $\mathrm{D}^{1}$ & $\begin{array}{l}-4,10 \\
(1,59) \\
{[0,010]}\end{array}$ & $\begin{array}{l}-4,39 \\
(1,89) \\
{[0,020]}\end{array}$ & $\begin{array}{c}-12,41 \\
(2,72) \\
{[0,000]}\end{array}$ & $\begin{array}{l}-7,20 \\
(2,55) \\
{[0,005]}\end{array}$ \\
\hline $\mathrm{D}^{2}$ & $\begin{array}{l}-0,73 \\
(1,03) \\
{[0,000]}\end{array}$ & $\begin{array}{l}-0,39 \\
(1,57) \\
{[0,806]}\end{array}$ & $\begin{array}{c}-10,48 \\
(1,68) \\
{[0,000]}\end{array}$ & $\begin{array}{c}-80,07 \\
(1,67) \\
{[0,000]}\end{array}$ \\
\hline $\mathrm{D}^{1} \times \mathrm{NEF}$ & $\begin{array}{c}0,61 \\
(00,34) \\
{[0,068]}\end{array}$ & $\begin{array}{l}0,97 \\
(0,38) \\
{[0,011]}\end{array}$ & $\begin{array}{l}1,59 \\
(0,58) \\
{[0,006]}\end{array}$ & $\begin{array}{l}0,83 \\
(0,54) \\
{[0,124]}\end{array}$ \\
\hline $\mathrm{D}^{2} \times \mathrm{NEF}$ & $\begin{array}{l}-0,02 \\
(0,23) \\
{[0,908]}\end{array}$ & $\begin{array}{l}0,14 \\
(0,39) \\
{[0,719]}\end{array}$ & $\begin{array}{c}1,21 \\
(00,38) \\
{[0,002]}\end{array}$ & $\begin{array}{l}00,83 \\
(0,38) \\
{[0,031]}\end{array}$ \\
\hline$n$ & 638 & 614 & 663 & 639 \\
\hline $\begin{array}{l}\mathrm{R}^{2} \text { within } \\
\mathrm{R}^{2} \text { between } \\
\mathrm{R}^{2} \text { overall }\end{array}$ & $\begin{array}{l}00,81 \\
00,95 \\
00,87\end{array}$ & & $\begin{array}{l}0,48 \\
0,16 \\
0,32\end{array}$ & $\begin{array}{l}0,50 \\
0,11 \\
0,32\end{array}$ \\
\hline
\end{tabular}

Notas: (Desviación estándar en paréntesis.)

[Estadístico $p$ en corchetes.]

un proceso $\operatorname{AR}(2)^{42}$. El estimador puntual de la expectativa condicional de precio es, entonces,

$$
\hat{p}_{i, t}=\hat{c}+\hat{\delta}_{1} \times p_{i, t-1}+\hat{\delta}_{2} \times p_{i, t-2}
$$

La estimación de (4.1) con $\hat{p}_{i, t}$ como variable dependiente se presenta en la columna 4 del Cuadro $\mathrm{N}^{\circ} \mathrm{B} 3$ (para comparar, hemos disponible en $t$. 
reproducido nuestra estimación trimestral de (4.1), la columna 6 del Cuadro $\mathrm{N}^{\circ}$ 8, en la columna 3 del Cuadro $\mathrm{N}^{\circ}$ B.3).

Aunque algo más pequeños, los coeficientes de pendiente mantienen el signo de las regresiones anteriores. De manera similar, todos los coeficientes de las variable resultan altamente significativos, con la excepción de $\delta_{1}$, el coeficiente de interacción entre $D^{1}$ y NEF (estadístico $p=0,124)$. Pero como el coeficiente de NEF, $\hat{\beta}$, se reduce en valor absoluto desde 3,24 hasta 1,96, un test de Wald de la hipótesis nula $\beta+$ $\delta_{1}+\delta_{2}=0$ no puede rechazarse a ningún nivel estándar de significancia (estadístico $p=0,430$ ).

\section{REFERENCIAS}

Adelman, M.: “Comment on the ' $\mathrm{H}$ ' Concentration Measure as a Numbers-Equivalent”. En Review of Economics and Statistics 59, 99-101, 1969.

Alvarado, I. y K. Charmel: "The Rapid Rise of Supermarkets in Costa Rica”. En Development Policy Review 20, 473-485, 2002.

Baldwin, J.: The Dynamics of Industrial Competition. Nueva York: Cambridge University Press, 1998.

Bartelsman, E. y M. Doms: "Understanding Productivity: Lessons from Longitudinal Microdata”. En Journal of Economic Literature 38, 569-594, 2000.

Bartelsman, E., J. Haltiwanger y S. Scarpetta: "Microeconomic Evidence of Creative Destruction in Industrial and Developing Countries”. World Bank Policy Research Paper No 3464, 2004.

Baumol, W., J. Panzar y R. Willig: Contestable Markets and the Theory of Industry Structure. Nueva York: Harcourt Brace Jovanovich, 1982.

Benavente, J., A. Galetovic y R. Sanhueza: "La Dinámica Industrial y la Financiación de las Pyme”. En El Trimestre Económico 72, 217-254, 2005.

Bresnahan, T.: "Empirical Studies in Industries with Market Power”. En R. Schmalensee y R. Willig (eds.), Handbook of Industrial Organization, volumen 2. Amsterdam: North Holland, 1989.

Cabrera, A., S. de la Cuadra, A. Galetovic y R. Sanhueza: "Las pyme: quiénes son, cómo son y qué hacer con ellas”. Mimeo, 2002.

Calderón, A.: "El Modelo de Expansión de las Grandes Cadenas”. En Revista de la Cepal 90, 151-170, 2006.

Caves, R.: "Industrial Efficiency in Six Nations: Introduction and Summary". En R. Caves (ed.), Industrial Efficiency in Six Nations. Cambridge: MIT Press, 1992.

"Industrial Organization and New Findings on the Mobility and Turnover of Firms”. En Journal of Economic Literature 36, 1947-1982, 1998.

Chávez, M.: “The Transformation of Mexican Retailing with Nafta”. En Development Policy Review 20, 503-513, 2002.

Codron, J-M., Z. Boushina, F. Fort, E. Coudel y A. Puech: "Supermarket in Low-income Mediterranean Countries: Impact on Horticulture Systems”. En Development Policy Review 22, 587-602, 2004. 
Coloma, F., J. P. Montero y J. Tarziján: “Análisis económico fusión D\&S y Falabella: informe final”. Mimeo, 2007.

Dries, L., T. Reardon y J. F. M. Swinner: "The Rapid Rise of Supermarkets in Central and Eastern Europe: Implications for the Agrifood Sector and Rural Development”. En Development Policy Review 22, 525-556, 2004.

Ellickson, P.: "Does Sutton Apply to Supermarkets? En Rand Journal of Economics 38, 43-59, 2007.

Evans, W., L. Froeb y G. Werden: "Endogeneity in the Concentration-Price Relationship: Causes, Consequences, and Cures”. En Journal of Industrial Economics 31, 203-255, 1993.

Faiguenbaum, S., J. A. Berdegué y T. Reardon: “The Rapid Rise of Supermarkets in Chile: Effects on Dairy, Vegetable, and Beef Chains”. En Development Policy Review 22, 459-471, 2004.

Farina, E.: "Consolidation, Multinationalization, and Competition in Brazil: Impact on Horticulture and Dairy Products Systems”. En Development Policy Review 20, 441-457, 2002.

Galetovic, A. y R. Sanhueza: "Un análisis económico sobre competencia y supermercados en Chile”. Mimeo, 2006.

Geroski, P.: Market Dynamics and Entry. Oxford: Basil Blackwell, 1991.

Goldman, A.: "Supermarkets in China: The Case of Shanghai". En International Review of Retail, Distribution \& Consumer Research 10, 1-21, 2000.

Gómez-Lobo, A. y A. González: "La relación entre los precios de los alimentos y la concentración de los supermercados en Chile: evidencia de un modelo dinámico de panel y análisis de las fusiones propuestas en la industria”. Mimeo, 2007.

Gutman, G. E.: "Impact of Rapid Rise of Supermarkets on Dairy Products Systems in Argentina”. En Development Policy Review 20, 409-427, 2002.

Humphrey, J.: "The Supermarket Revolution in Developing Countries: Tidal Wave of Tough Competitive Struggle”. En Journal of Economic Geography 7, 433-450, 2007.

Klemperer, P. y M. Meyer: "Supply Function Equilibria in Oligopoly under Uncertainty”. En Econometrica 57, 1243-1277, 1989.

Levy, D., M. Bergen, S. Dutta y R. Venable: "The Magnitude of Menu Costs: Direct Evidence From Large US Supermarket Chains”. En Quarterly Journal of Economics 112, 791-825, 1997.

Lira, L.: "Cambios en la Industria de los Supermercados: Concentración, Hipermercados, Relaciones con Proveedores y Marcas Propias”. En Estudios Públicos 97, 135160, 2005.

Lira, L., R. Rivero y R. Vergara: "Entry and Prices: Evidence from the Supermarket Sector”. En Review of Industrial Organization 31, 237-260, 2007.

Lira, L. y M. Ugarte: "Relación entre Concentración, Economías de Escala y Tamaño de Mercado en la Industria de Supermercados de Chile: Un Análisis Empírico”. Documento de Trabajo $\mathrm{N}^{\circ}$ 16, Centro de Economía de la Empresa, Universidad de los Andes, 2007.

Lira, L., M. Ugarte, y R. Vergara: "Economías de escala, concentración y precios en la industria de supermercados”. Mimeo, 2007.

- "Prices and Market Structure: An Empirical Analysis of the Supermarket Industry in Chile”. Documento de Trabajo No 24, Centro de Economía de la Empresa, Universidad de los Andes, 2008. 
Reardon, T. y J. Berdegué: “The Rapid Raise of Supermarkets in Latin America: Challenges and Opportunities for Development”. En Development Policy Review 20, 371-388, 2002.

Reardon, T. y A. Gulati: “The Supermarket Revolution in Developing Countries”. En IFPRI Policy Brief 2, 2008.

Reardon, T., S. Henson y J. Berdegué: “'Proactive Fast-Trucking’ Diffusion of Supermarkets in Developing Countries: Implications for Market Institutions and Trade”. En Journal of Economic Geography 7, 399-431, 2007.

Reardon, T. y J. F. M. Swinnen: "Agrifood Sector Liberalization and the Rise of Supermarkets in Former Stated-controlled Economies: A Comparative Overview”. En Development Policy Review 22, 515-523, 2004.

Reardon, T., P. Timmer, C. Barret y J. Berdegué: "The Rise of Supermarkets in Africa, Asia and Latin America”. En American Journal of Agricultural Economics 85, 1140-1146, 2003.

Rodríguez, E., M. Berges, K. Casellas, R. Di Paola, B. Lupin, L. Garrido y N. Gentile: "Consumer Behaviour and Supermarkets in Argentina". En Development Policy Review 20, 429-439, 2002.

Rojas, P.: “Informe económico fusión Falabella-D\&S”. Mimeo 2007.

Schwentesius, R. y M. A. Gómez: "Supermarkets in Mexico: Impacts on Horticulture Systems”. En Development Policy Review 20, 487-502, 2002.

Singh, V. y T. Zhu: "Pricing and Market Concentration in Oligopoly Markets". Mimeo, Carnegie Mellon, 2006.

Slade, M.: "Optimal Pricing with Costly Adjustment: Evidence from Retail-Grocery Prices”. En Review of Economic Studies 65, 87-107, 1998.

Stigler, G.: "The Dominant Firm and the Inverted Umbrella”. En Journal of Law and Economics 8, 167-172, 1965.

Sutton, J.: Sunk Costs and Market Structure. Cambridge: MIT Press, 1991.

Symeonidis, G.: The Effects of Competition: Cartel Policy and the Evolution of Strategy and Structure in British Industry. Cambridge: MIT Press, 2002.

Tybout, J.: "Manufacturing Firms in Developing Countries: How Well Do They Do, and Why". En Journal of Economic Literature 38, 11-44, 2000.

Weiss, L.: Concentration and Price. Cambridge: MIT Press, 1989. 